\title{
Evaluation of Corrosion of Aluminum Based Reactor Fuel Cladding Materials During Dry Storage
}

by

H. B. Peacock Jr.

Westinghouse Savannah River Company

Savannah River Site

Aiken, South Carolina 29808

R. L. Sindelar

P. S. Lam

T. H. Murphy

This paper was prepared in connection with work done under the above contract number with the U. S. Department of Energy. By acceptance of this paper, the publisher and/or recipient acknowledges the U.S. Government's right to retain a nonexclusive, royalty-free license in and to any copyright covering this paper, along with the right to reproduce and to authorize others to reproduce all or part of the copyrighted paper. 


\section{EVALUATION OF CORROSION OF ALUMINUM- BASE REACTOR FUEL CLADDING MATERIALS DURING DRY STORÄEE (U)}

H. B. Peacock, Jr.; R.' L. Sindelar, P. S. Lam, and T. H. Murphy

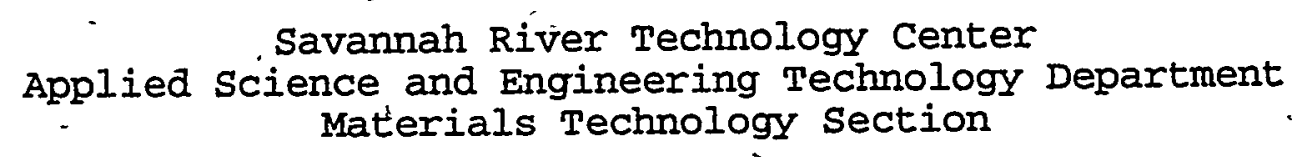

Publication Date: November 1995

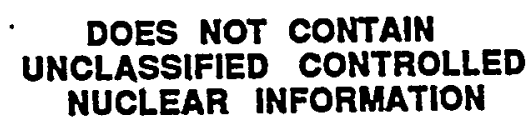

ADC \&

Reviewing

Official:

CLASSIFIED CONTROLLED

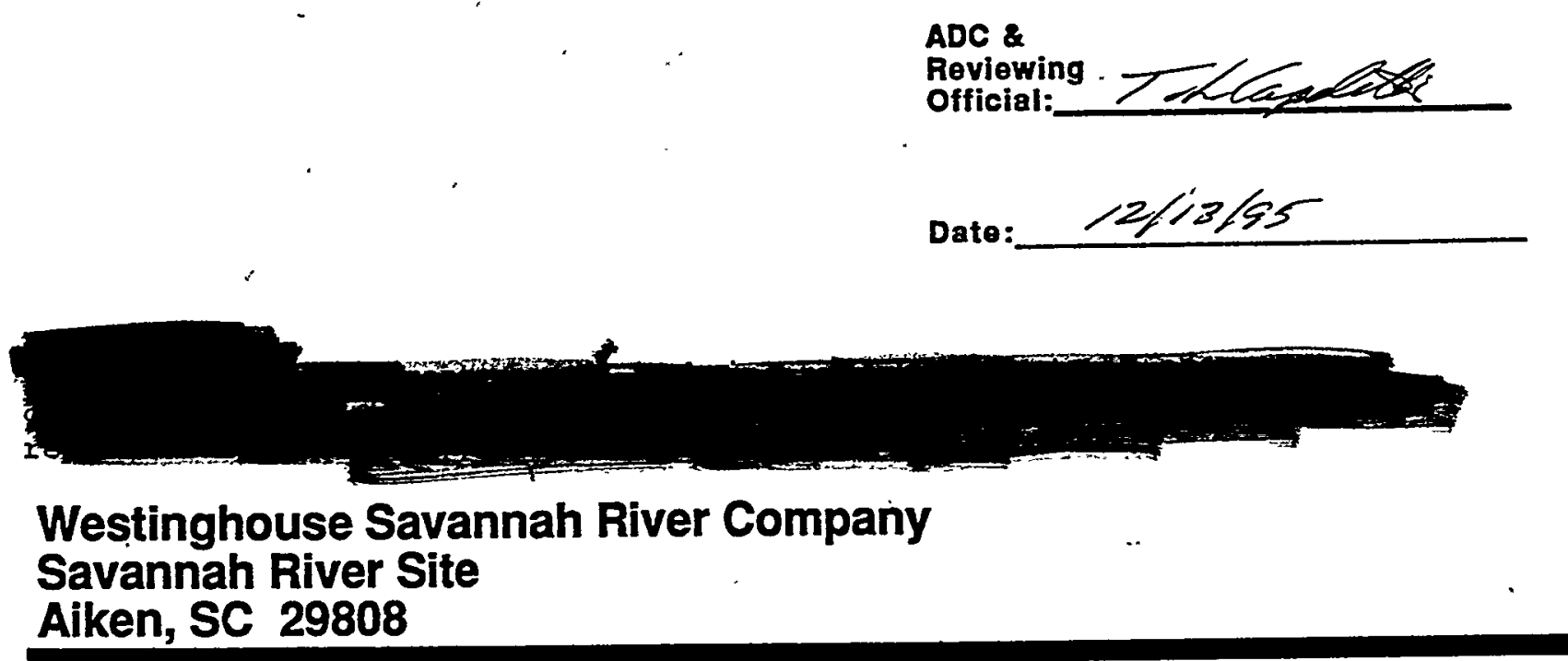

This document was prepared in connection with work done under Contract No. DE-AC09-89SR18035 with the U. S. Department of Energy. 


\section{DISCLAIMER}

This report was prepared as an account of work sponsored by an agency of the United States Government. Neither the United States Government nor any agency thereof, nor any of their employees, makes any warranty, express or inplied, or assumes any legal liability or responsibility for the accuracy, completeness, or usefulness of any information, apparatus, product, or process disclosed, or represents that its use would not infringe privately owned rights. Reference herein to any specific commercial product, process, or service by trade name, trademark, manufacturer, or otherwise does not necessarily constitute or imply its endorsement, recommendation, or favoring by the United States Government or any agency thereof. The views and opinions of authors expressed herein do not necessarily state or reflect those of the United States Government or any agency thereof.

This report has been reproduced directly from the best available copy.

Available to DOE and DOE contractors from the Office of Scientific and Technical Information, P.O. Box 62, Oak Ridge, TN 37831; prices available from (615) 576-8401.

Available to the public from the National Technical Information Service, U.S. Department of Commerce, 5285 Port Royal Road, Springfield, VA 22161.

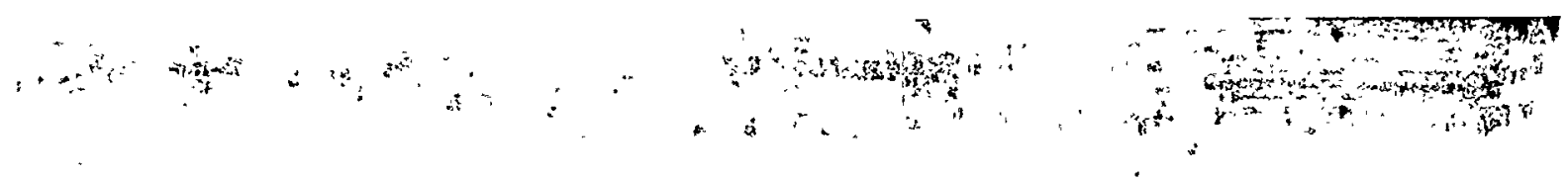




\section{DISCLAIMER}

Portions of this document may be illegible in electronic image products. Images are produced from the best available original document. 
DQCUMENT:

TITLE:

TASR:
WSRC-TR-95-0345

EVALUATION OF CORROSION OF ALUMINUM-BASE REACTOR FUEL CLADDING MATERIALS DURING DRY STORAGE (U)

WSRC-RP-94-360, Rev. 1 PLAN FOR DEVELOPMENT OF ACCEPTANCE CRITERIA FOR INTERIM DRY STORAGE OF AL-CLAD SPENT NUCLEAR FUEL (U)

\section{APPROVALS}

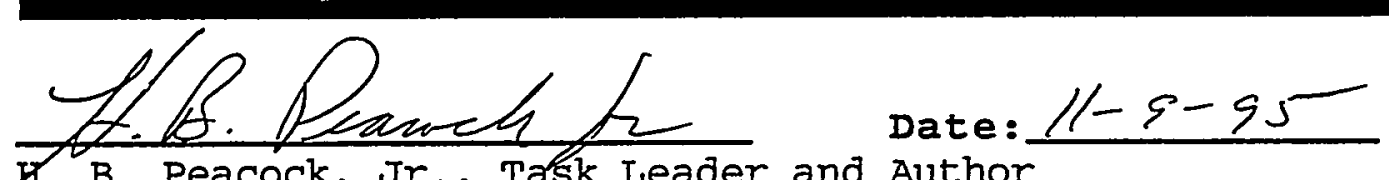

71. B. Peacock, Jr., Task Leader and Author

Materials Applications \& Corrosion Technology Group MATERIALS TECHNOLOGY SECTION

A Xeirdelar

R. I. Sindelar, Task Leader and Author

Materials Applications \& Corrosion Technology Group MATERIALS TECHNOLOGY SECTION

PSLem Date: $12-12-95$

P. S. Iram, Author

Materials Applications \& Corrosion Technology Group MATERIALS TECHNOLOGY SECTION

Pracy purphy

Materials Applications \& Corrosion Technology Group

MATERIALS TECHNOLOGY SECTION

$\frac{\text { Pls } 3 \text { P. E. Zapp, Technical Reviewer }}{\text { P. }}$

Date: $12-8.95$

MATERIALS TECHNOLOGY SECTION

hatrapty

Nं. C. Iyer, Manager

Materials Applications \& Corrosion Technology Group

MATERIALS TECHNOLOGY SECTION

$7-<$ ientobs

Date: $12 / 1 / 3 / 55$

T. L. Capeletti, Manager

MATERIALS TECHNOLOGY SECTION

7. R. Mulphy

Date: $12-11-95$

Spent Fuels Programs

EXCESS FACILITIES \& REACTOR FUEL STORAGE DIVISION 
Table of Contents

Page

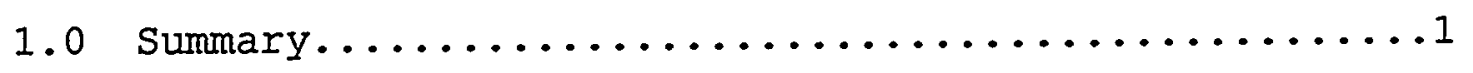

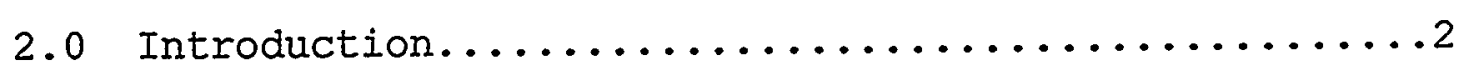

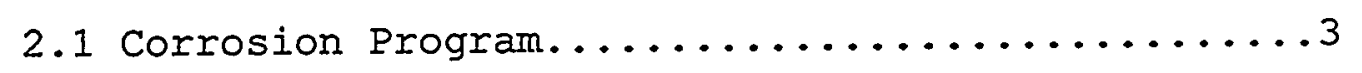

3.0 Atmospheric Corrosion..................

3.1 General Corrosion................... 5

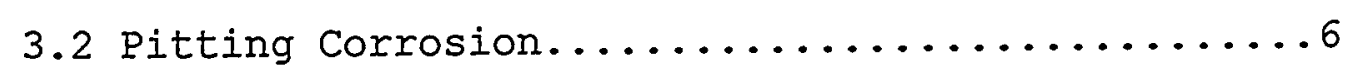

4.0 Gamma Radiolysis....................

5.0 Corrosion Models.....................

6.0 Materials Characterization................. 10

7.0 Experimental Methods....................

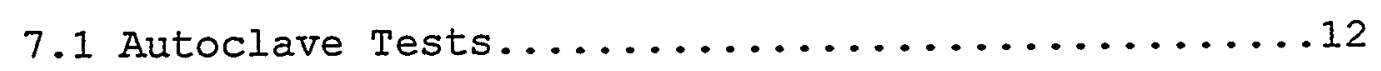

7.2 Capsule Tests.........................

7.3 Pitted Specimens.................... 18

8.0 Experimental Results....................

8.1 Autoclave Tests........................

8.8.1 Condensed Water Tests................ 19

8.1 .2 Nitric Acid Water Tests................ 20

8.2 Capsules Tests........................

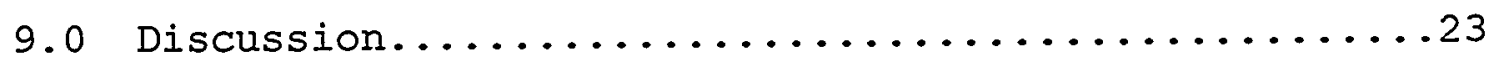

9.1 Corrosion of Aluminum...................

9.2 Corrosion of Aluminum-Uranium Alloys.........25

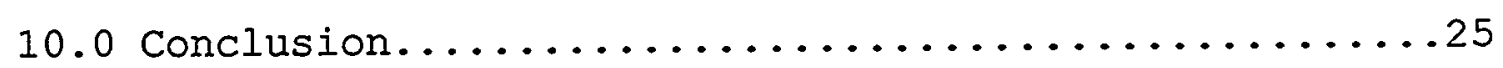

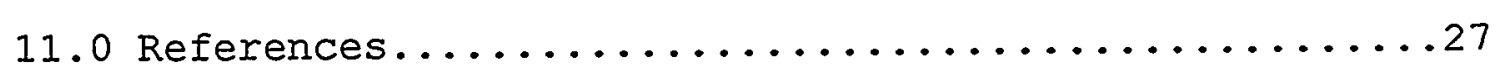




\section{List of Tables}

Table Number

I. Composition Comparison between US and Canadian

Alloys in Corrosion Testing...................29

II. Typical Compositions of Cladding Materials for

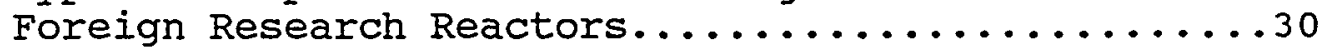

III. X-Ray Fluorescence Analysis of Aluminum Alloy Materials for Corrosion Testing and Aluminum Company of America Composition Limits............. 31

IV. Chemical Analysis of Condensate water used in Corrosion Testing..................... 32

V. Parameters for Arrhenius-Power Law Corrosion Model $\left(w=A e^{-Q n / R T} t^{n}\right)$ in Water Vapor at $100 \%$ Relative Humidity. .33 
Iist of Figures

Figure Number

Page

1. Optical Photomicrographs of As-Received 1100,

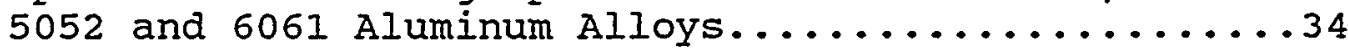

2. Typical Pressure and Temperature chart for Corrosion Testing in the Autoclave.................. 35

3. Design Drawing for Corrosion Test Capsules........36

4. Photograph of Fabricated Corrosion Capsule........37

5. Typical Photograph of Aluminum Coupons after

Removal from the Autoclave at $200{ }^{\circ} \mathrm{C} \ldots . . \ldots . . . . .38$

6. Typical XRD Chart Confirming Boehmite Formation

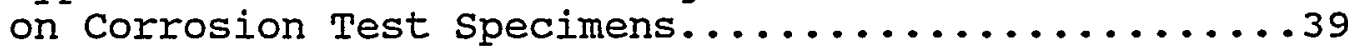

7. Weight Gain as a Function of Time for 1100 Aluminum at $100 \%$ Relative Humidity and at 150

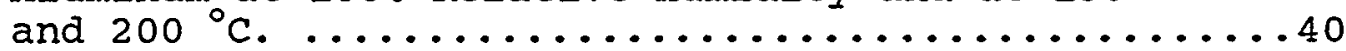

8. Weight Gain as a Function of Time for 5052

Aluminum at 100\% Relative Humidity and at 150

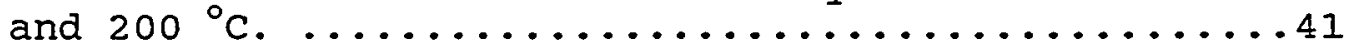

9. Weight Gain as a Function of Time for 6061

Aluminum at $100 \%$ Relative Humidity and at 150

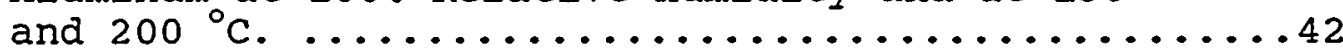

10. Aluminum Oxide on 6061 Alloy Coupons Exposed to an Atmosphere of Water Vapor at $100 \% \mathrm{Rh}$ and $200{ }^{\circ} \mathrm{C}$

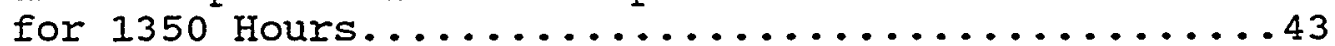

11. Montage of optical and Scanning Electron Photomicrographs of a Blistered Area from an Aluminum 10 wt\% Uranium Hot Rolled Alloy Exposed to $100 \%$ Relative Humidity for 96 Hours (4days) ...............................44

12. Corrosion of 1100, 5052 and 6061 Aluminum Alloys in an Atmosphere Containing $\mathrm{NO}_{x}$ Gases and $100 \%$ Relative Humidity for 1 Week..........45

13. Pitted Surfaces of 5052 Aluminum alloy Exposed to an Atmosphere Containing $\mathrm{NO}_{x}$ Gases and $100 \%$ Relative Humidity for 1 Week..............46 
14. Weight Gain as a Function of Time and Relative Humidity for 1100 Aluminum Alloy in Atmospheres of Water Vapor and Water Vapor plus $\mathrm{NO}_{\mathrm{x}}$ Gases....47

15. Weight Gain as a Function of Time and Relative Humidity for 5052 Aluminum Alloy in Atmospheres of Water Vapor and Water Vapor plus $\mathrm{NO}_{\mathrm{x}}$ Gases....48

16. Weight Gain as a Function of Time and Relative Humidity for 6061 Aluminum Alloy in Atmospheres of Water Vapor and Water Vapor plus $\mathrm{NO}_{x}$ Gases....49

17. Water Vapor and Hydrogen Gas Pressures Calculated for 1100, 5052 and 6061 Aluminum Specimens Inside a closed system During Corrosion............50

18. I100 Aluminum Metal Loss vs Exposure Time at 150 and $200{ }^{\circ} \mathrm{C}$ and at $100 \%$ Relative Humidity....51

19. 5052 Aluminum Metal Loss vs Exposure Time at 150 and $200{ }^{\circ} \mathrm{C}$ and at $100 \%$ Relative Humidity....52

20. 6061 Aluminum Metal Loss vs Exposure Time at 150 and $200{ }^{\circ} \mathrm{C}$ and at $100 \%$ Relative Humidity....53

21. Corrosion inside a $3.2 \mathrm{~mm}$ Diameter Pit Exposed to $100 \%$ Relative Humidity (Water Vapor for

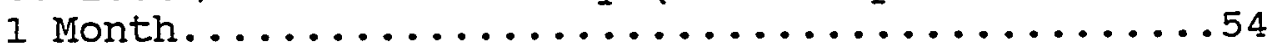




\section{0 summary}

Temperature and relative humidity effects on the high temperature corrosion of aluminum-base cladding alloys was investigated for dry storage of spent nuclear fuel elements. The aluminum alloys covered 1100, 5052 and 6061 commercial materials which have compositions similar to some foreign research reactor (FRR) cladding alloys. The studies included tests in both a high temperature autoclave and small stainless steel capsules to mock up storage conditions. For the autoclave, the relative humidity was constant at $100 \%$, and the temperatures were either $150^{\circ} \mathrm{C}$ or $200^{\circ} \mathrm{C}$. These situations represented the extreme conditions expected for spent fuel storage. Corrosion models were fit to the autoclave data obtained over the 1400 hours of. testing and were used to predict long term storage behavior of aluminum-base fuel elements in saturated environments.

In the capsule tests, the effect of decreasing relative humidity with time was evaluated for various aluminum alloys. The initial relative humidity ranged from $20 \%$ to $100 \%$. Calculations of the relative humidity changes were made to explicate the decrease in humidity and the build up of hydrogen gas within a closed system due to corrosion reactions. Corrosion equations were determined from autoclave models. Corrosion models will be fit to capsule data once testing is complete. A dependency on alloy type, temperature, relative humidity, and the environment was observed during corrosion testing in the autoclave and in the specially designed capsules.

Extruded aluminum-uranium fuel tube specimens with 8001 aluminum cladding and containing machined through- 
clad pits were tested at similar vapor space conditions. optical metallography of sections through the pits showed both thin and thick oxide layers for the uranium-aluminum alloy. The thick layers were in the vicinity of uraniumaluminide particles.

Completion of various corrosion tests in progress will allow development of models having a higher degree of confidence for long term prediction of the corrosion behavior of cladding alloys. Aluminum alloys may exhibit paralinear corrosion behavior so test longer than 1400 hours must be done to determine if a change in corrosion mechanisms occur.

\subsection{INTRODUCTION}

Savannah River nuclear production reactors were operated and many of the research and test reactors continue to be operated using aluminum clad fuel elements with either aluminum-uranium or aluminum-uranium silicide fuel. In the United states, aluminum-clad spent nuclear fuel (SNF) assemblies were previously reprocessed to recover the fissile material. Currently, reprocessing facilities are shut down, and the fuel assemblies are stored in water basins pending decisions on final. disposition. Some countries are already using the dry storage concept for aluminum-based fuels as an alternative to interim basin storage. In the US, dry storage is a proposed option for temporary storage prior to final disposition of aluminumbased fuels. Before a licensable facility is built, acceptance criteria need to be established to ensure 50 years of safe storage.

Degradation of the fuel due to corrosion of the aluminum is a limiting factor for dry storage in moist and oxygenated environments. If reactor fuel elements are to be 
stored to limit degradation, then conditions must be specified for maximum cladding temperature, cover gas properties, and arying procedures. Under ideal conditions where moisture and oxygen are excluded from the storage canister, and the temperature is low, aluminum-clad fuels can be stored without oxidation. However, one must verify, to the satisfaction of the Department of Energy (DOE) or a licensing committee, that these conditions either exist and will remain for the entire storage period or show that deviations from these conditions have limited, acceptable effects. Also, the state of the fuels must be predicted for long term storage under applicable worst-case 'conditions if the desired storage conditions can not be maintained.

This report provides an evaluation of the corrosion behavior of aluminum cladding alloys and aluminum-uranium alloys at conditions relevant to dry storage. The details of the corrosion program are described and the results to date are discussed.

\subsection{CORROSION PROGRAM}

Temperature, humidity, and environmental conditions affect the corrosion behavior of various aluminum alloys. An evaluation of degradation mechanisms have indicated that cladding temperatures for storage of foreign research reactor (FRR) and domestic reactor fuels should not exceed $200^{\circ} \mathrm{C}^{1}$ The worst case expected is an air environment with $100 \%$ relative humidity. However, gamma radiolysis produces various gaseous species, including nitrogen oxide gases, when air is present, and if moisture is present, nitric acid can be produced. 
The corrosion testing program is part of the overall program ${ }^{2}$ to develop limits for drying and storage of aluminum-clad SNF. Corrosion is being evaluated using aluminum coupons either in an autoclave or in specially designed capsules containing either water or water with nitric acid additions to produce nitrogen oxide gases.

Research reactor fuel elements are stored under water in storage basins after irradiation. In many cases, the water quality has not been maintained. Aluminum alloys tend to form pits in poorly controlled water quality environments. Fuel elements generally have complex shapes and can not be disassembled for inspection before dry storage; therefore, any pits in the cladding are sites for potential corrosion of the uranium bearing core. To evaluate corrosion behavior of pitted elements, experimental studies were conducted by exposing extruded tube specimens containing different size pits machined either part-way or through the 8001 aluminum cladding. The cores contained a cast alloy of $18 \mathrm{wt} \%$ and $33 \mathrm{wt} \%$ uranium in aluminum.

\subsection{ATMOSPHERIC CORROSION}

Although aluminum is very reactive, it has good corrosion resistance in oxidizing environments. In air, its stability is due to a layer of amorphous aluminum oxide which forms rapidly on exposed aluminum surfaces. The molecular volume of the oxide is 1.5 times the volume of aluminum consumed which puts the oxide surface in compression and allows some deformation without rupturing the oxide film. ${ }^{3}$ Water, present as vapor in the atmosphere, can cause continuous growth of a hydrated oxide with a corresponding consumption of aluminum especially at high temperatures and humidities. 


\subsection{GENERAL CORROSION}

General corrosion in aqueous environments occurs by an electrochemical process and is effected by the chemical composition of the corrosive medium or electrolyte. Water, one of the major components in the atmosphere, condenses on the surface of metals and serves as the electrochemical path for corrosion reactions. The water or moisture content in air can be expressed by its relative humidity ( $R h$ ) which is defined as the ratio of the water vapor pressure to the saturation vapor pressure at a given temperature. It is generally expressed as a percentage.

Water from a humid environment can be deposited on the surface of a metal by condensation followed by absorption. The amount of moisture adsorbed on the surface varies with the relative humidity and temperature. Volpe determined. that, at $20^{\circ} \mathrm{C}$ in moderately humid atmospheres of about $30 \%$ $\mathrm{Rh}$, more than 10 monolayers of water are present. At $100 \%$ relative humidity, the adsorbed layer more than doubled. Investigators ${ }^{5}$ have also found that there is a critical humidity between 40 and $70 \%$ below which practically no corrosion occurs at room temperature. The critical value for the relative humidity appears to depend on the electrolyte composition, the previous amount of corrosion and possibly temperature.

When aluminum is first exposed to the atmosphere, a thin continuous film of amorphous oxide quickly forms. On continued exposure, a layer of oxide grows on the already thin amorphous layer. It may have several different crystalline phases depending on the reaction temperature and the presence of water. For example, at temperatures less than about $80{ }^{\circ} \mathrm{C}$ bayerite $\left(\mathrm{Al}_{2} \mathrm{O}_{3} \cdot 3 \mathrm{H}_{2} \mathrm{O}\right)$ is stable and above 80 ${ }^{\circ} \mathrm{C}$ boehmite $\left(\mathrm{Al}_{2} \mathrm{O}_{3} \cdot \mathrm{H}_{2} \mathrm{O}\right)$ is the predominant oxide form. These 
hydrated oxides that are formed when aluminum is exposed to water are reported to be highly porous. 6

Water vapor in the atmosphere contains both dissolved solids and gases, particularly in industrial areas. Aluminum compounds that have been found in the corrosion layers include oxides and hydrated variants of sulfates and chlorides. Nitrates have not been detected on surfaces of aluminum exposed to natural environments. ${ }^{7,8}$ The reason, most likely, is because all nitrates are water soluble, and in natural environments would be leached from the surface by excess water. Nguyen and Foley ${ }^{9}$ found that the nitrate ion is reduced by aluminum but not aluminum oxide; thus, interaction with the aluminum substrate occurs when there is a defective oxide surface.

\subsection{PITTING CORROSION}

Aluminum may exhibit pitting, a localized corrosion phenomenon, when there is a breakdown of the passive film. Halides (chlorides) and sulfates accelerate localized corrosion $^{10}$. Because the outer layer of hydrous aluminum oxide is often porous, adsorbed water tends to penetrate the oxide layer and locally attack the aluminum substrate. Additionally, pitting of aluminum alloys occurs at sites of discontinuities such as impurity-rich regions, scratches or other imperfections. ${ }^{5}$ Localized corrosion is generally considered a multi-step process. The steps given by Foley ${ }^{11}$ include:

a) Adsorption of a reactive anion on the oxide surface.

b) Either a chemical reaction between the adsorbed anion and the oxide or an anion exchange with the oxide lattice.

c) Thinning of the oxide layer by dissolution

d) Direct attack of the aluminum surface by the anion.

The maximum pit depth generally varies as the cube root of the exposure time. ${ }^{5,12}$ The equation is: 


$$
\mathrm{d}=\mathrm{Kt} \mathrm{t}^{1 / 3}
$$

where $d$ is the maximum pit depth, $t$ is the exposure time, and $\mathrm{K}$ is a constant related to the material and the environment.

\subsection{GAMMA RADIOLYSIS}

In a radiation field, oxides of nitrogen are produced by gamma radiolysis of air. These compounds can further react with moisture to produce nitric acid. The concentration of species formed depends on (1) the nature of the ionizing radiation (2) the dose rate (3) the total dose and (4) impurities.

Primak and Fuchs ${ }^{13}$ studied the behavior of metals exposed to ionizing radiation in Argonne's $\mathrm{CP}-3$ reactor in humid air at $28^{\circ} \mathrm{C}$. They reported that certain metals and alloys are subject to nitric acid corrosion when irradiated in moist air environments. Nitrogen and oxygen combined in the gas phase to coat nitric-acid susceptible metals in the presence of water vapor. It was found that aluminum, cobalt, copper, inconel, lead and nickel were coated with nitrates after irradiation. Additionally, steinberg ${ }^{14}$ reported results of in-pile capsule irradiation of nitrogenoxygen gas mixtures. Relatively high concentrations of nitrogen oxides were built up. More than $90 \%$ of the oxygen in the mixture was converted to gaseous oxides of $\mathrm{N}_{2} \mathrm{O}_{4}, \mathrm{NO}_{2}$ and $\mathrm{N}_{2} \mathrm{O}$ at steady state conditions. Johansson ${ }^{15}$ observed significant increased corrosion of aluminum when $\mathrm{NO}_{2}$ was added to $\mathrm{SO}_{2}$ in high humid atmospheres. The reaction of $\mathrm{NO}_{2}$ with moisture can occur according to the following chemical equation: 


$$
2 \mathrm{NO}_{2}+\mathrm{H}_{2} \mathrm{O} \text { (moisture) } \rightarrow \mathrm{HNO}_{2}+\mathrm{H}^{+}+\mathrm{NO}_{3}^{-}
$$

The $\mathrm{HNO}_{2}$ produced by this reaction is very unstable and is known only in solution. ${ }^{16}$ It reacts with additional water to produce nitric acid and No gas. Further evidence of increased corrosion due to radiolysis was discovered at the

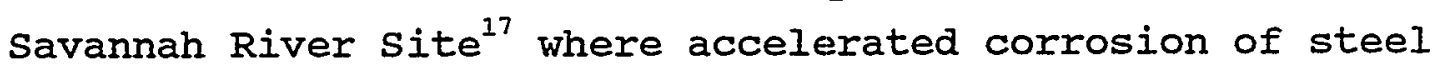
occurred in the reactor process room.

Thus, nitric acid forms on the metal surface to influence corrosion behavior. In a closed system, however, reactions producing nitrogen oxides and corrosion of the metal stop once the moisture and oxygen in the air are depleted by subsequent oxidation reactions with metal surfaces.

\subsection{CORROSION MODELS}

The basic corrosion process is well understood at high temperature. At an interface, a reacting component, a compound or metallic ion, is soluble in the oxide film. Ionic compounds have appreciable ionic conductivity due to Schottky and/or Frenkel defects. Also, metal cations diffuse interstitially or by vacancy diffusion in the oxide lattice. Metallic ions after moving through the oxide film combine with oxygen (or water) near the surface to form the metal or hydrated oxide. The growth rate for general corrosion is related to the weight gain of the material and is proportional to the ion concentration gradient. From this relationship, the general power law follows:

$$
w=(c t)^{n}
$$


where $w$ is the oxide thickness or weight gained, $c$ is a constant, $t$ is the exposure time and $n$ is an exponent theoretically equal to 0.5 for parabolic growth. The constant $C$ is related to the concentration of the diffusing species so that its effects may be modeled using the Arrhenius relationship. The resulting equation becomes:

$$
W=A e^{-Q n / R T} t^{n}
$$

where $A$ is a constant dependent on the material and humidity, $Q$ is the activation energy, $R$ is the universal gas constant, and $\mathrm{T}$ is the absolute temperature.

Low temperature corrosion tends to follow a logarithmic or inverse logarithmic law. Eley and Wilkinson ${ }^{18}$ developed a logarithmic model based on the assumption that metal atoms diffuse through the film to react at the surface with oxygen and that the activation energy is a function of film structure and thickness. The general equation developed was

$$
x=k \log \left(k_{1} t+k_{2}\right)
$$

where $X$ is the film thickness or weight gain, $t$ is the exposure time, and $K, K_{1}$ and $K_{2}$ are constants.

Cabrera and Mott ${ }^{19}$ attributed the movement of cations through the oxide by strong electric fields set up in the film. When metal ions moved in one direction without recombining with the aluminum substrate, the inverse logarithmic relationship resulted:

$$
1 / x=-c \log c_{1} t+c_{2}
$$


where $x$ is the oxide thickness, $t$ is the exposure time and $C, C_{1}$ and $C_{2}$ are constants. Godard ${ }^{20}$ determined the oxide film growth over a five year period for some Canadian aluminum alloys in air at room temperature and at various humidities. The oxide was most likely bayerite because of the low temperature exposure in humid air. However, Godard assumed that the film was $\mathrm{Al}_{2} \mathrm{O}_{3}$. The data fit the inverse logarithmic relationship and values for the constants in the inverse law were determined for each alloy. Constants reported in the table for $\mathrm{CA}-3 \mathrm{~S}$ alloy could not be verified using the experimental data given in graphical form in the report. Data for other alloys used in the test were not given; nevertheless, the corrosion response was reported to be similar to $\mathrm{CA}-3 \mathrm{~S}$ alloy.

The composition of some of the Canadian alloys that Godard tested are compared with alloys used in this investigation in Table $I$. The Canadian alloys CA-2S, CA-65S and $C A-57 S$ have very similar compositions to 1100,6061 and 5052 aluminum alloys, respectively.

\subsection{MATERIALS CHARACTERIZATION}

Research and test reactor fuel elements are clad with aluminum alloys that have been qualified for reactor service. A list of some of the cladding materials along with the maximum allowable alloying elements is given in Table II for FRR fuels. Because these alloys were not available, the corrosion tests reported here were carried out using 1100, 6061 and 5052 aluminum alloys. Although the compositions of these alloys do not identically match the FRR materials, alloys similar in composition are expected to exhibit similar corrosion behavior. $\mathrm{x}$-ray fluorescence analysis of aluminum alloys used in this investigation are 
given in Table III along with composition limits specified by the Aluminum Company of America. ${ }^{a}$

The 1100 aluminum alloy is a commercially pure material (99\%) containing iron, silicon and copper with other trace impurities. This material has been used as a cladding material for heavy water reactor targets at the Savannah River Site. Alloy 5052 contains typically 2.5\% magnesium and $0.25 \%$ chromium. This high magnesium alloy has alloying elements similar to CERCA'S $S^{b}$ AG alloys and NUKEM'S ${ }^{c}$ AlMg alloys. Aluminum 6061 is a precipitation hardening alloy containing typically about $1 \%$ magnesium, $0.6 \%$ silicon and $0.3 \%$ chromium. This alloy is used as a cladding material for the high flux research reactor (HFIR) fuel elements in the US and for cladding on other reactor fuel elements made by Babcock and Wilcox ${ }^{d}$. Some FRR cladding alloys have slightly higher copper and either higher or lower magnesium contents.

The aluminum coupons used in the corrosion tests were obtained from Metal Samplese. Compositions of these alloys were determined by $\mathrm{X}$-ray fluorescence to confirm compositional values reported on the certified Test Report. The samples were machined from 1100-H14, 5052-H32 and 6061T6 sheet material and wet ground on a belt sander to give a 600 grit surface finish.

Optical photomicrographs of the three alloys in the asreceived condition are shown in Figure 1 . The etching solution to bring out the microstructure was a mixture of 90

a Aluminum Company of America, Pittsburgh, PA.

b Compagnie pour l'Etude et la Realisation de Combustibles Atomiques, Romans-sur-Isere, France.

c NUKEM GmbH, Hanau, Fed. Rep. of Germany.

d Babcock \& Wilcox Company, Lynchburg, Virginia, U.S.A.

e Metal Samples Co., Inc., Munford, Alabama, 36268. 
$\mathrm{ml}$ of water and $10 \mathrm{ml}$ of hydrofluoric acid. Elongated grains in the cold worked microstructure for the 1100 and 5052 alloys can be seen in (a) and (b) while equiaxed grains of the solution annealed and aged 6061 are evident in (c). Scanning electron microscopy and $x$-ray spectroscopy was used to identify the basic composition of precipitates. Precipitates consist of (1) aluminum-iron-copper in 1100, (2) aluminum-iron-chromium in 5052 and(3) aluminum-ironcopper-chromium in 6061.

\subsection{EXPERIMENTAI METHODS}

Condensate water was used in the tests so atmospheric impurities, characteristic to the Savannah River site, could be included in the test matrix. The water was obtained using a condensing coil and collected in a polyethylene bottle. Instrumental chemical analysis for elemental impurities was done using inductive coupled plasma emission spectroscopy (ICP). Anion analysis was done by ion chromatography. The results for major elements are given in Table IV along with $\mathrm{pH}$ and conductivity measurements.

\subsection{Autoclave tests}

Corrosion tests were carried out in a one-gallon, stainless steel autoclave that was manufactured by Autoclave Engineers ${ }^{f}$. Tests were done at 1.50 and $200^{\circ} \mathrm{C}$ using both condensed water and a solution of condensed water and nitric acid. The solution of $10 \mathrm{wt} \%$ concentrated nitric acid in condensed water, having a pH of approximately 1, was used to provide nitrogen oxide vapors inside the autoclave at $150^{\circ} \mathrm{C}$. The oxide vapors simulated the build up of these gases by

f Autoclave Engineers, Inc., Erie, Pennsylvania, 16512-5051 
radiolysis inside storage casks where similar conditions may exist.

The aluminum test coupons were isolated from the stainless steel vessel wall to eliminate effects on corrosion behavior. A Teflon ${ }^{\mathrm{TM}}$ plate was bolted to the top of the vessel and aluminum hangers were attached to the plate with aluminum nuts to support the specimens. Shallow grooves in the hangers kept the specimens apart to minimize crevice corrosion. Up to 28 specimens could be tested at a time. All coupons were cleaned before beginning the test using acetone to remove oils and were rinsed thoroughly in distilled water and alcohol before drying. No attempt was made to remove the as-received oxide layer from the aluminum coupons.

The autoclave vessel was helium leak checked prior to corrosion testing. The sensitivity of the leak detector was $1 \times 10^{-6} \mathrm{ccHe} / \mathrm{sec}$. Before corrosion testing, $150 \mathrm{ml}$ of condensate water or acid solution was added to the vessel. This quantity of water or solution exceeded the minimum amount needed to maintain saturated vapor conditions throughout the test. After the controller was turned on, it took about one hour to reach steady-state temperature conditions.

The vessel pressure was measured using a sensotec pressure transducer, model TJE/71a3-18 and a HM signal conditioner with RS-232 output for data acquisition. A chromel-alumel thermocouple inside the thermowell of the vessel measured the temperature in the vicinity of the test specimens. Temperature data were read and transmitted to

в Sensotec, 1200 Chesapeake Ave., Columbus, Ohio. 
the acquisition system using a Newport INFINITY temperature meter. ${ }^{\mathrm{h}}$

The relative humidity was measured using a Vaisala HMP234 humidity and temperature instrument ${ }^{i}$. The probe read data from inside the autoclave for temperatures up to $180{ }^{\circ} \mathrm{C}$ maximum. It has a pressure rating of 100 bars (1450 psi) and an accuracy of about $+/-2 \%$ at 90 to $100 \% \mathrm{Rh}$.

The software for data acquisition was written in Microsoft $c$ language. Temperature, pressure and relative humidity was recorded as a function of time. Data were taken at 0.25 hour intervals. A typical pressuretemperature chart is shown in Figure 2 .

Air inside the autoclave was at atmospheric pressure at the beginning of the test. As the autoclave temperature increased the air pressure and the water vapor pressure increased so that the total pressure inside the autoclave was the sum of both pressures. Air inside the vessel was vented to the atmosphere for approximately 15 seconds when the temperature reached $100{ }^{\circ} \mathrm{C}$; thus, leaving mostly water vapor present during corrosion testing.

Relative humidity inside the autoclave was also calculated from measured temperature and pressure data as a backup to measured values. The saturation water vapor pressure for the calculation was determined as a function of temperature using steam table data. ${ }^{21}$ calculated values for the relative humidity were necessary at temperatures above $180^{\circ} \mathrm{C}$, which was the maximum operating temperature of the humidity probe and for acid solution tests. The derivation

h Newport Electronics, Inc., 2229 South Street, Sanata Ana, CA.

i Vaisala Inc., Woburn, MA 01801-1068 
combined Dalton's law of partial pressures, the perfect gas law, constant volume relations, and the definition of relative humidity. The derived equation for the relative humidity $(\%)$ is:

$$
R h=\left(1 / P_{S}\right)\left(100 P_{t}+K[T+273]\right)
$$

where $P_{S}$ is the saturation vapor pressure in pounds per square inch absolute (psia) at temperature $T$ in degrees Celsius and $P_{t}$ is the total measured pressure (psia) inside the autoclave. The total pressure includes the pressure due to both water vapor and air, if present. The value of the constant $\mathrm{K}$ is determined from room temperature conditions and represents air inside the autoclave before the top is bolted in place. The value of $\mathrm{K}$ is given by:

$$
K=\left(R h_{r} \times P_{S}-1470\right) /\left(T_{I}+273\right)
$$

where $\mathrm{Rh}_{\mathrm{r}}$ is the relative humidity of the room air in percent and $P_{S}$ is the saturation vapor pressure at room temperature $T_{r}$ in degrees celsius. When the autoclave is vented to remove the air inside the vessel, the value of $K$ is equal to zero.

The autoclave was used to test corrosion behavior at $100 \%$ vapor conditions. Although various starting humidities can be obtained by Iimiting the amount of water added before startup, it was impossible to control the humidity with this system because condensation occurred on cooler exposed surfaces. This reduced the amount of water vapor inside the autoclave and resulted in much lower relative humidity than expected. 
The corrosion studies of aluninum alloys were conducted by loading pre-weighed specimens inside the vessel and heating in a saturated vapor atmosphere. After specified time intervals, the autoclave was shut down and the samples removed. They were dried for about 30 minutes at room temperature in a desiccator under a vacuum of approximately 10-2 torr. This was done to remove any moisture from the surface which would effect weight gain measurements.

\subsection{Capsule Tests}

Humidity effects on the corrosion behavior of aluminum alloys at high temperatures have not been investigated in a closed system environment. To evaluate these effects, tests were made using stainless steel capsules. Inside the capsules, the relative humidity at the beginning of the tests was adjusted to give either $20,50,80$ or $100 \%$ at the test temperature of $150^{\circ} \mathrm{C}$. This test design approximated the storage conditions under which fuel rods may be loaded into a cask in air and sealed for long term storage.

Capsules for corrosion testing of aluminum coupons and tube ring specimens were made from 1.5-inch-diameter stainless steel pipe caps. The capsule test represented conditions anticipated for storage of aluminum clad fuel in stainless steel casks. A step was machined into the bottom and top caps, so when assembled and seal welded, the specimens would be shielded from weld spatter. Stainless steel pins were placed in the bottom cap to hold the aluminum specimens in place. A 1/8-inch-diameter liquidfill tube was gas-tungsten-arc (GTA) welded to the top cap to inject condensate water or condensate-acid solution into the sealed capsule. The design is shown in Figure 3. 
The volume of the top and bottom caps was measured prior to capsule assembly by filling each with water using a burette. From these measurements, the amount of water required for various relative humidities inside the capsule was calculated based on thermodynamics of steam at the test temperature.

After placing the aluminum coupons on the pins, the top and bottom caps were assembled and joined using a fullpenetration electron-beam weld. Each capsule contained one sample each of 1100,5052 and 6061 alloys so each material could be tested under identical conditions. All of the capsules were pressure tested at $200 \mathrm{psi}$, and 12 randomly selected capsules were helium leak tested. They were leak tight to the limit of $1 \times 10^{9} \mathrm{ccHe} / \mathrm{sec}$, the limit of the leak detector. Photograph of a finished capsule is shown in Figure 4 .

Each capsule was first weighed and then filled with the appropriate solution using a microsyringe. The capsule was re-weighed after filling to verify that the correct amount of solution had been added. The fill tube was immediately clamped to seal the solution inside, and the top portion of the fill tube crimped and cut off. The clamping technique was verified by a bubble-test in water using 90 psi air pressure. The end of the fill tube was autogenous GTA welded within an hour to completely seal the liquid solution inside the capsule. After welding, the clamp was removed and the finished capsule weighed. Upon completion of each corrosion test, the capsule was again weighed, and the weight compared to the original weight to verify that no leaks had occurred in the closed system. A dummy capsule was heated and weighed along with the test capsules to 
obtain a correction factor for stainless steel oxidation during corrosion testing.

The capsules were placed inside an electrically heated oven at $150^{\circ} \mathrm{C}$, and certain capsules were removed after 1 and 3 months; others in the test matrix will be removed after 6 and 12 months. The furnace was monitored daily to verify the temperature. After removal from the furnace, the capsules were separated at the weld centerline using a pipe cutter. The aluminum samples were removed from the pins using plastic-tip tweezers. Any water that may have condensed on the surface was removed by air drying before weighing.

Each aluminum coupon was weighed three separate times on a 5 place microbalance and the weights averaged to obtain weight gain data for the aluminum coupons. Standards were weighed before each sample to verify balance calibration.

\subsection{PitTed SPEcimens}

Pits were milled in the cladding of a coextruded fuel tube that was extrusion clad with $0.030-i n c h$ thick 8001 aluminum alloy. The size of the pits were $1 / 32$ inch $(0.79$ $\mathrm{mm}), 1 / 16$ inch $(1.6 \mathrm{~mm})$ and $1 / 8$ inch $(3.2 \mathrm{~mm})$ in diameter. For each diameter, the pits were milled to depths of 0.010 , $0.020,0.025$, and 0.031 (through-clad) inch. Pit depths were confirmed using optical metallography. The specimens were tested in both the autoclave at $200{ }^{\circ} \mathrm{C}$ and $100 \% \mathrm{Rh}$ and in capsules under the conditions described above. 


\subsection{EXPERIMENTAL RESULTS}

\subsection{Autoclave Tests}

\subsubsection{Condensed Water Tests: Typical coupons from} autoclave tests at $200^{\circ} \mathrm{C}$ and $100 \% \mathrm{Rh}(100 \%$ condensed water vapor) are shown in Figure 5 for 6061 aluminum. Corrosion was evident by the disappearance of longitudinal 600 grit scratches and dulling of the surface. $X$-ray diffraction (XRD) of the oxide confirmed that boehmite formed at both $150^{\circ} \mathrm{C}$ and $200^{\circ} \mathrm{C}$. Typical XRD pattern obtained from the analysis is shown in Figure 6 .

Weight gain data (micrograms/ $\mathrm{dm}^{2}$ ) at 150 and $200^{\circ} \mathrm{C}$ are plotted as a function of time at $100 \%$ Rh in Figures 7,8 , and 9 for 1100, 5052 and 6061 alloys, respectively. Power law equations with the Arrhenius term were fit to the data (up to 1400 hours) using numerical least squares analysis. In the figures, solid curves are for $200^{\circ} \mathrm{C}$ and broken curves for $150^{\circ} \mathrm{C}$. Values for the constants and exponents are given in Table $V$ for all alloys.

The thickness of the oxide layer after about 1400 hours (“2 months) at $200^{\circ} \mathrm{C}$ was measured from $500 \mathrm{X}$ optical photomicrographs using a $5 \mathrm{X}$ magnifier containing a metric measuring scale. Typical photographs for the 6061 alloy are presented in Figure 10. About 25 thickness readings were made randomly from five different photographs of selected specimens. The readings were averaged to give the arithmetic mean thickness of $6.1,6.2$ and 4.4 microns after 1400 hours exposure at 100\% $\mathrm{Rh}$ for 1100, 5052 and 6061, respectively. The calculated values for the oxide thickness from weight gain data were $6.0,6.5$ and 4.3 microns for the 
1100, 5052 and 6061 alloys which show excellent agreement with measured values.

Pitted specimens that were placed in the autoclave at $200^{\circ} \mathrm{C}$ and $100 \% \mathrm{Rh}$ showed corrosion of the aluminum-18 wt\% uranium alloy core only when the core was initially exposed by through-the-cladding pits. There was no cladding penetration by oxidation in areas where the cladding had been thinned to $0.13 \mathrm{~mm}$ ( $0.005 \mathrm{inch})$. At the bottom of the pits, black oxide formed. It was identified by XRD as $\mathrm{U}_{4} \mathrm{O}_{9}$.

An aluminum-10 wt\% uranium alloy that had been hot rolled showed significant corrosion after four days at $200^{\circ} \mathrm{C}$ and $100 \% \mathrm{Rh}$, as measured by weight gain. Aluminides from the corroded matrix were observed in the oxide layer using both SEM and optical metallography. There were areas on the specimen where there were practically no surface oxide while in blistered areas, large amounts of oxide were present with uranium aluminides scattered in the oxide layer as shown in Figure 11 .

\subsubsection{Nitric Acid Water Test: When corrosion} experiments were carried out at $100 \% \mathrm{Rh}$ and with nitric acid to simulate radiolysis, severe corrosion of all specimens took place as shown in Figure 12. In one week the samples corroded so badly that it was difficult to removed them from the hangers. Aluminum oxide sluffed from the surfaces and was found in the bottom of the autoclave. X-ray diffraction confirmed that both the sluffed oxide and the oxide on the sample surfaces was boehmite. No evidence of nitric oxides or compounds were found in the aluminum oxide samples.

The average metal loss for each alloy was determined following chemical removal of the boehmite layer. The results are $1.6,2.9$, and 2.6 microns for 1100,5052 and 
6061 aluminum alloy, respectively. A severely pitted surface was observed after the oxide was removed from the 5052 alloy. A photograph of the surface is shown in Figure 13. The measured maximum pit depth was $1 \mathrm{~mm}$. The other aluminum alloys did not exhibit pitting corrosion.

\subsection{Capsule Tests}

Capsule test results for weight gain vs time after one and three months exposure to either $20,50,80$ or $100 \%$ nominal relative humidity are shown in Figure 14 for 1100, Figure 15 for 5052 and Figure 16 for 6061 . The solid curves in the figures represent corrosion at $150^{\circ} \mathrm{C}$ in condensed water vapor while broken curves represent corrosion at $150^{\circ} \mathrm{C}$ in a nitric oxide vapor environment. For a given humidity, the curves exhibit a decreasing corrosion rate for all alloys with increasing time.

The extent of corrosion in condensed water vapor for aluminum alloys at any given time is less for lower initial humidity conditions. For example, after 2000 hours for 1100 aluminum, the weight gain at $100 \% \mathrm{Rh}$ in condensed water is about $42,000 \mu \mathrm{g} / \mathrm{dm}^{2}$, but at $20 \% \mathrm{Rh}$ the weight gain is practically zero. This phenomena applies to 1100 and 6061 alloys tested and defines the limiting humidity level for corrosion at $150^{\circ} \mathrm{C}$. The high magnesium alloy 5052 continues to corrode slightly at $20 \% \mathrm{Rh}$.

Corrosion in an acid environment for all alloys tested continues to follow the power law model observed for condensed water at $150^{\circ} \mathrm{C}$, but this environment produces more corrosion of the aluminum alloys at any given instant. Results also show decreased corrosion with decreasing humidity levels. In an acid-air environment, corrosion 
proceeds at a rapid rate when compared to water vapor corrosion; thus, oxygen and moisture are used up at a faster rate in the closed system.

The decrease in the humidity inside the closed system was calculated assuming that only water vapor caused corrosion of the aluminum alloys. The initial capsule conditions were $100 \% \mathrm{Rh}$ and $150^{\circ} \mathrm{C}$ temperature. Using the experimental weight gain equations, the amount of water consumed and the hydrogen build up inside the capsule containing one sample each of 1100, 5052 and 6061 were determined during corrosion reactions from the chemical reaction

$$
2 \mathrm{Al}+4 \mathrm{H}_{2} \mathrm{O} \rightarrow \mathrm{Al}_{2} \mathrm{O}_{3} \cdot \mathrm{H}_{2} \mathrm{O}+3 \mathrm{H}_{2} \text { (gas) }
$$

A $70 \mathrm{ml}$ vessel was used, and the gases were assumed to obey the perfect gas law and Dalton's law of partial pressures. The decrease in water vapor from saturated conditions was then used to calculate the specific volume of vapor and the relative humidity inside the capsule at the exposure temperature.

The results of the incremental calculations are shown in Figure 17. The water vapor decreases and the hydrogen pressure increases as corrosion of the aluminum proceeds to completion. Initially the water vapor inside the capsule was at the saturation conditions at a pressure of 4.9 $\mathrm{kg} / \mathrm{cm}^{2}(69.0 \mathrm{psia})$. After 5.6 years all of the vapor would be used up and the hydrogen pressure increased to about 3.9 $\mathrm{kg} / \mathrm{cm}^{2}$ ( $55 \mathrm{psia}$ ) inside the vessel. Although oxygen in the air also contributes to corrosion, its effect was not modeled in this calculation. 


\subsection{DIscussION}

\subsection{CORROSION OF ALUMINUM}

Autoclave results show that corrosion of aluminum alloys in saturated water vapor at 150 and $200^{\circ} \mathrm{C}$ follows the power law relationship with an increase in corrosion with temperature in accordance with an Arrhenius relation.

Corrosion data were fit using the Arrhenius-power law equation for each alloy so that the weight gain equation was a function of both temperature and time. ${ }^{22}$ The correlation coefficients $\left(R^{2}\right)$ for the fits to the 1100, 5052 and 6061 data were $0.93,0.87$ and 0.91 , respectively. The exponents $(\mathrm{n})$ in the equations were found to be $0.41,0.55$ and 0.45 . These values are close to the theoretical value of 0.5 for high temperature parabolic corrosion. Using the experimental values for the exponent $n$, the activation energy (Q) becomes 22,20 and $16 \mathrm{kcal} / \mathrm{mole}$ for 1100,5052 and 6061 aluminum alloys, respectively. The activation energy tends to vary with alloy type. The published value of the activation energy for the growth of hydrous oxide films on aluminum, in the temperature range of 40 to $100^{\circ} \mathrm{C}$, is $18.7 \mathrm{kcal} / \mathrm{mole}{ }^{23}$ The experimental values show good agreement with the published value for pure aluminum.

A summary of atmospheric corrosion data of aluminum alloys is given in Reference 7 . In weather at ambient temperatures, impurity species break down the passive films and corrosion effects are manifested as pits. Corrosion, measured by weight loss, depth of pitting, or loss of tensile strength, is observed to have an initial (up to 2 years duration) high rate after which it decreases to a low, approximately linear value. The metallurgical results from this present study at high temperatures and with atmospheric 
condensate from SRS shows a uniform film of boehmite forms on all alloys at all conditions, except for 5052 alloy under nitric oxide vapor conditions. Uniform growth in thickness would be expected to continue until spallation at a film thickness of approximately 50 microns. A thickness of boehmite of approximately 50 microns has been observed as the maximum thickness for Materials Test Reactor fuels. ${ }^{24}$

Extrapolation of this data (converted to oxide thickness of boehmite) to 50 years gives average oxide film thicknesses of 19, 33 and 21 microns for 1100, 5052, and 6061 , respectively at $150^{\circ} \mathrm{C}$ and 59,134 and 52 microns for at $200^{\circ} \mathrm{C}$, respectively. Equations for metal loss due to corrosion were determined from the weight gain data and are plotted in Figures 18, 19 and 20 for 1100, 5052 and 6061 aluminum alloys. The corresponding thickness of metal consumed after 50 years is found to be 11,19 and 12 microns at $150^{\circ} \mathrm{C}$ and 33,76 and 30 microns at $200{ }^{\circ} \mathrm{C}$, respectively. For a cladding of thickness of 762 microns ( 0.030 inch) this represents a decrease in thickness due to corrosion of less than $2.5 \%$ at $150^{\circ} \mathrm{C}$ and less than $10 \%$ at $200^{\circ} \mathrm{C}$ for all the alloys tested in this program.

The spread in data points shown in Figures 7, 8 and 9 for each time interval is relatively small at first but tends to become larger as corrosion continues, especially at $200^{\circ} \mathrm{C}$ for the 1100 and 5052 alloys. The 6061 aluminum alloy does not follow strictly this pattern. It is also noted that the data set for 5052 aluminum alloy at 1400 hours exposure and at $200^{\circ} \mathrm{C}$, lies above the power law equation. Although it may be due to sample variability, this observation is consistent with the fact that aluminum alloys have shown a transition from parabolic to linear oxidation at elevated temperatures. ${ }^{25}$ Further study is needed to evaluate aluminum corrosion for times greater than 1400 
hours at $200^{\circ} \mathrm{C}$. This may be due to a change in the corrosion mechanism for the alloy. Further study and corrosion tests for longer times are being done.

Calculations show that the decrease in relative humidity can be calculated as a function of time inside a closed storage system. After exposure, the water vapor inside the system is consumed in the corrosion reactions with aluminum to produce hydrated aluminum oxide. The hydrogen pressure increases to a value limited by the amount of hydrogen generated in the corrosion reaction of aluminum and water.

\subsection{Corrosion of ALUMINUM-URANIUM ALLOYS}

Figure 21 shows the black oxide that formed in the pitted aluminum-uranium specimen that was tested in the autoclave at $200^{\circ} \mathrm{C}$. The oxide was stripped from the surface and analyzed using XRD. It was found to contain $\mathrm{U}_{4} \mathrm{O}_{9}$ and boehmite. Initial results from metallographic examination of a sectioned pit show that thick and thin oxide areas form across the bottom of the pitted area. This observation is consistent with studies of an aluminum $10 \mathrm{wt} \%$ uranium alloy which also showed blistering of the material in areas where thick oxide deposits occurred. Further analysis is needed to determine the corrosion mechanism for aluminum-uranium alloys.

\subsection{CONCLUSION}

Corrosion experiments were performed under various humidity and temperature conditions that are relevant to dry storage of aluminum-clad spent nuclear fuels. The results showed a dependency on alloy type, temperature, humidity 
levels, and vapor species $\left(\mathrm{NO}_{\mathrm{x}}\right)$. The corrosion behavior was modeled with a power law containing an Arrhenius term. The equations, based on corrosion data for 1400 hours, allow predictions for long-term (50+ years) storage as a function to time and temperature. Metal loss, if general corrosion continues in the prescribed manner and no sluffing of the oxide film occurs, is predicted to be about 33 ( $1.3 \mathrm{mils}$ ), $76(3.0 \mathrm{mils})$, and $30(1.2 \mathrm{mils})$ microns for 1100,5052 and 6061 aluminum alloys after 50 years of storage in a constant environment of $100 \%$ relative humidity and $200^{\circ} \mathrm{C}$, respectively.

A critical humidity level near approximately $20 \%$ was observed at $150^{\circ} \mathrm{C}$ for 1100 and 6061 aluminum. As corrosion continues in a closed system, oxygen and water vapor are depleted. Eventually, all corrosion is expected to stop. . Therefore, predictions made using the equations in this report are expected to give an upper bound for metal lost for extended times (years).

Studies will continue (1) to evaluate paralinear oxidation and (2) to develop models for a closed system so prediction can be made for long-term storage under these conditions. An uncertainty analysis of all test data will be done to give further confidence in the results. These tests do not include the effects of radiation on the oxide characterisitcs. Further experiments using irradiated fuels in the hot cells are planned to validate these results for irradiated fuels. A final report will be issued at the conclusion of the testing program. 


\subsection{References}

1 Sindelar, R. I. and Peacock, H. B., "Evaluation of Degradation During Interim Dry Storage of Auminum Alloy Clad Spent Nuclear Fuel," WSRC-TR-95-0344, September 1995.

2 Sindelar, R. L. and Peacock, H. B., "Plan for the Development of Acceptance Criteria for Interim Dry Storage of Al-Clad Spent Nuclear Fuel (U)," WSRC-RP94-360 (Rev. 1), February 1995.

3 Wefers, K., "Properties and Characterization of Surface Oxides on Aluminum Alloys," Aluminum, Vol 57(11), pp $722-726$, 1981 .

4 Volpe, I. Proceedings of the 10th International Congress on Metallic Corrosion, 1987.

5 Vernon, W. H. J., "A Laboratory Study of the Atmospheric Corrosion of Metals," Trans. Farad. Soc., Vol 27, p.255, 1931 .

6 Alwitt, R. S., "The Growth of Hydrous Oxide Films on Aluminum," The Journal of the Electrochemical Society, Vol. 121, 1322, 1974.

7 Godard, H. P., in The Corrosion of Light Metals, Godard, H. P., Jepson, W. B. Gothwell, M. R., and Dane R. I., Editors, P3, John Wiley \& Sons, Inc., New York, 1967.

8 Friel, J. J., "Atmospheric Corrosion Products on Al, $\mathrm{Zn}$, and Alzn Metallic Coatings," Corrosion, 42, 422, 1986

9 Nguyen, T. H. and Foley, R. T., Journal of the Electrochemical Society, Vol 127, 2563, 1980.

10 Graedel, T. E., "Corrosion Mechanisms for Aluminum Expsoed to the Atmosphere," J. Electrochem. Soc., Vol. 136, No. 4, p. 204C, April 1989.

11 Foley, R. T., "Localized Corrosion of Aluminum Alloys A Review," Corrosion, Vol. 42, No. 5, p. 277, 1986.

12 Maiya P. S. and Kassner, T. F., "Role of Atmospheric Corrosion of Aluminum alloys in Viability of Intrinsicsurface Methods for Tagging Military Hardware," Argonne National Laboratory, ANL/ACTV-91/6, (1991).

13 Primak, W. and Fuchs, L. H., "Transportation of Matter and Radioactivity by Ionized Air Corrosion," Physics 
Today, p.15, September 1954; "Nitrogen Fixation in a Nuclear Reactor," Nucleonics, March 1955.

14 steinberg, M. "Process Radiation Development, Chemonuclear and Radiation Chemical Processes Research and Development," Isotopes and Radiation Technology, Vol. 4, No. 2, p. 142-155, winter, 1966-1967.

15 Johansson, L. G., in Corrosion Effects of Acid Deposition and Corrosion of Electronic Materials, (PV 86-6) F. Sinclair, Editors, p. 267, The Electrochemical Society Softbound Proceedings Series, Pennington, J., 1986.

16 Nebergall, W. H. and Schmidt, F. C., college Chemistry, D.C. Heath and Company, Boston, p. 357, 1957.

17 Longtin, F. B., "Air Radiolysis," Savannah River Report, DPSP-69-1403, September 19, 1969.

18 Hart, R. K., "oxidation of Aluminum in Dry and Humid Oxygen Atmospheres," Trans. Faraday Soc. 53, 1020, 1957.

19 Cabrera, N. and Mott, N. F., Rep. Progr. Phys. 12,163, 1949.

20 Godard, H. P., "Oxide Film Growth over Five Years on Some Aluminum Sheet Alloys in Air of Varying Humidity at Room Temperature," J. Electrochem. Soc., Vol. X, p. $354,1967$.

21 Keenan, J. H., and Keys, F. G., Thermodynamic Properties of steam, Thirty-third Printing, wiley Printing Company, January 1961.

Lam, P.S., Peacock, Jr., H.B., and Sindelar, R.I., "Models for Corrosion Response of Aluminum to Environments of Dry Storage," WSRC-TR-95-0346, November 1995. (to be issued)

Alwitt, R. S., "The Growth of Hydrous oxide Films on Aluminum," J. Electrochem. Soc., pp. 1322-1327, October 1974 .

Hofman, G. I., Private communication, Argonne National Laboratory, Chicago Illinois.

Dillon, R.I., "observations on the Mechanisms and Kinetics of Aqueous Aluminum Corrosion," Corrosion, vol. 15, pp. 13t-16t, 1959. 


\section{Table I}

\section{COMPOSITION COMPARISON BETWEEN US AND CANADIAN ALLOYS IN CORROSION TESTING}

\begin{tabular}{|c|c|c|c|c|c|c|c|}
\hline & \multicolumn{7}{c|}{ Alloy Designation } \\
\hline Elements, wt.\% & 1100 & CA-2S & 5052 & CA-57S & 6061 & CA-65S \\
\hline $\mathrm{Cu}$ & 0.13 & 0.01 & 0.01 & 0.02 & 0.3 & 0.33 \\
\hline $\mathrm{Fe}$ & 0.52 & 0.47 & 0.28 & 0.25 & 0.5 & 0.40 \\
\hline $\mathrm{Si}$ & 0.10 & 0.16 & 0.12 & 0.2 & 0.61 & 0.58 \\
\hline $\mathrm{Mg}$ & 0.01 & - & 2.52 & 2.35 & 1.02 & 0.99 \\
\hline $\mathrm{Mn}$ & 0.01 & - & 0.02 & - & 0.03 & 0.03 \\
\hline $\mathrm{Cr}$ & 0.01 & - & 0.19 & 0.26 & 0.23 & 0.24 \\
\hline $\mathrm{Zn}$ & 0.01 & - & 0.01 & - & 0.02 & - \\
\hline $\mathrm{Ti}$ & 0.01 & - & 0.02 & 0.02 & 0.01 & - \\
\hline
\end{tabular}

*Reference: Godard, H.P., "Oxide Film Growth Over Five Years on Some Aluminum Sheet Alloys in Air of Varying Humidity at Room Temperature," J. Electrochem. Soc., Vol. 114, No. 4, April 1967. 


\section{Table III}

TYPICAL COMPOSITIONS OF CLADDING MATERIALS FOR FOREIGN RESEARCH REACTORS

\begin{tabular}{|c|c|c|c|c|c|c|c|}
\hline & \multicolumn{7}{|c|}{ Fuel Manufacturer* } \\
\hline & \multicolumn{3}{|c|}{ CERCA } & \multicolumn{3}{|c|}{ NUKEM } & $B \& W$ \\
\hline M & (1) & (6) & (S) & 2.X' & 16: & 2 & 5.1862 \\
\hline $\mathrm{Mg}$ & $1.1-1.4$ & $1.8-2.3$ & $2.5-3.0$ & $0.8-1.2$ & $0.7-1.1$ & $1.7-2.4$ & $0.8-1.2$ \\
\hline B & - & 0.001 & - & 0.001 & 0.001 & 0.001 & 0.001 \\
\hline $\mathrm{Cd}$ & - & 0.001 & - & 0.001 & 0.001 & 0.001 & 0.001 \\
\hline $\mathrm{Cu}$ & - & 0.008 & - & 0.008 & 0.008 & 0.008 & $0.2-0.40$ \\
\hline $\mathrm{Fe}$ & - & $0.2-0.4$ & - & $0.8-1.2$ & 0.45 & 0.40 & 0.70 \\
\hline $\mathrm{Si}$ & - & 0.3 & - & 0.30 & 0.30 & 0.30 & $0.40-0.80$ \\
\hline $\mathrm{Cr}$ & - & 0.3 & - & $0.2-0.5$ & 0.10 & 0.30 & $0.04-0.35$ \\
\hline $\mathrm{Mn}$ & - & 0.7 & - & $0.2-0.6$ & 0.15 & 0.30 & 0.15 \\
\hline $\mathrm{Ii}$ & - & 0.001 & - & 0.001 & 0.001 & 0.001 & 0.008 \\
\hline $\mathrm{Zn}$ & - & - & - & $0.06-0.14$ & 0.05 & 0.03 & 0.25 \\
\hline $\mathrm{Ti}$ & - & - & - & $0.02-0.08$ & - & 0.10 & 0.25 \\
\hline $\mathrm{Al}$ & - & Balance & - & Balance & Balance & Balance & Balance \\
\hline Others & - & 0.03 & - & 0.03 & 0.15 & 0.15 & 0.15 \\
\hline
\end{tabular}

* Reference: IAEA Guide Book on Fuels, pp41-47. 
Table III

X-RAY FLuORESCENCE ANALySIS OF ALUMINUM ALloy MATERIALS For CORROSION TESTING AND ALUMINUM COMPANY OF AMERICA COMPOSITION LIMITS

\begin{tabular}{|c|c|c|c|c|c|c|c|c|c|c|c|c|c|}
\hline & \multicolumn{13}{|c|}{ eight } \\
\hline 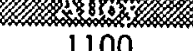 & 0.104 & 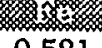 & 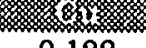 & 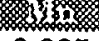 & 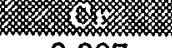 & 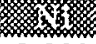 & 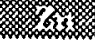 & 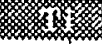 & 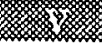 & x & 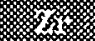 & 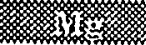 & 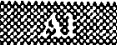 \\
\hline . & $0.104 \ldots$ & 0.521 & ה.128 & .0.005 & 0.007 & 0.009 & 0.009 & 0.007 & 0.008 & 0.011 & 0 & 0.012 & 99.17 \\
\hline$\frac{1100 \text { Limits }}{5052}$ & \multicolumn{2}{|c|}{1.0} & $0.05-2.0$ & 0.05 & - & - & - & 0.1 & & - & - & - & Bal. \\
\hline 5052 Limits & 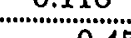 & 0.204 & 0.014 & 0.022 & 0.188 & 0.012 & 0.011 & 0.019 & 0.012 & 0.013 & 0.001 & 2.522 & 96.78 \\
\hline 6061 & \multicolumn{2}{|c|}{0.45} & 1.0 & . & $0.15-0.35$ & - & 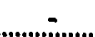 & $\therefore .$. & - & - & 0.10 & $2.2-2.8$ & Bal. \\
\hline 6061 Limits & $0.4-0.8$ & $\frac{0.491}{0.7}$ & $\frac{0.30}{0.15 \cdot 0.4}$ & $\frac{0.081}{0.15}$ & $\frac{0.228}{004-035}$ & 0.012 & $\frac{0.024}{0.025}$ & $\frac{0.012}{0.15}$ & 0.016 & 0.012 & 0 & 1.019 & 97.23 \\
\hline
\end{tabular}




\section{Table IV}

CHEMICAL ANALYSTS OF CONDENSATE WATER USED IN CORROSTON TESTING

\begin{tabular}{|c|c|}
\hline Calcium & 1.812 \\
\hline Magnesium & 0.423 \\
\hline Manganese & 0.131 \\
\hline Zinc & 0.493 \\
\hline Iron & 0.021 \\
\hline Sodium & 7.577 \\
\hline Phosphorus & 4.904 \\
\hline Silicon & 0.557 \\
\hline
\end{tabular}

\begin{tabular}{|c|c|}
\hline Cholride & 1.25 \\
\hline Formate & 2.85 \\
\hline Nitrate & $<1.5$ \\
\hline Sulfate & 7.49 \\
\hline
\end{tabular}

\begin{tabular}{|l|l|}
\hline $\begin{array}{l}\text { Conductivity } \\
\mu \text { siemens/cm }\end{array}$ & 52 \\
\hline Acidity $(\mathrm{pH})$ & 6.80 \\
\hline
\end{tabular}




\section{Table V}

PARAMETERS FOR ARRHENIUS-POWER LAW CORROSION MODEL $\left(W=A e^{\cdot Q n / R T} t^{n}\right)$ IN WATER VAPOR AT $100 \%$ RH.

\begin{tabular}{|c|c|c|c|}
\hline - = & 8 - & 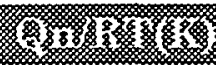 & (3) \\
\hline 1100 & $7.37 \times 10^{7}$ & 4500 & 0.4086 \\
\hline 5052 & $2.81 \times 10^{8}$ & 5600 & 0.5481 \\
\hline 6061 & $5.45 \times 10^{6}$ & 3600 & 0.4532 \\
\hline
\end{tabular}




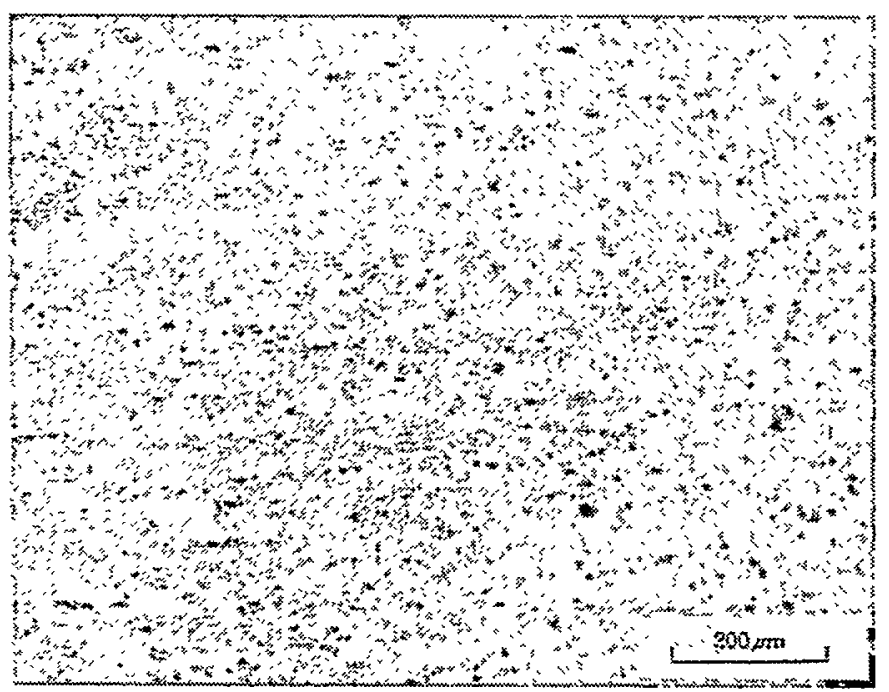

(a) 1100 Aluminum Alloy

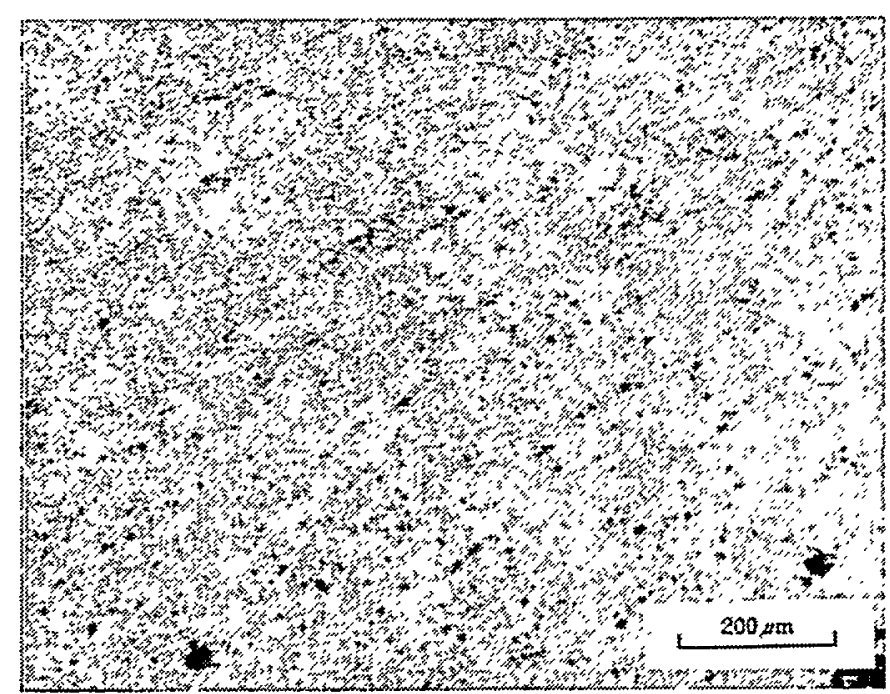

(b) 5052 Aluminum Alloy

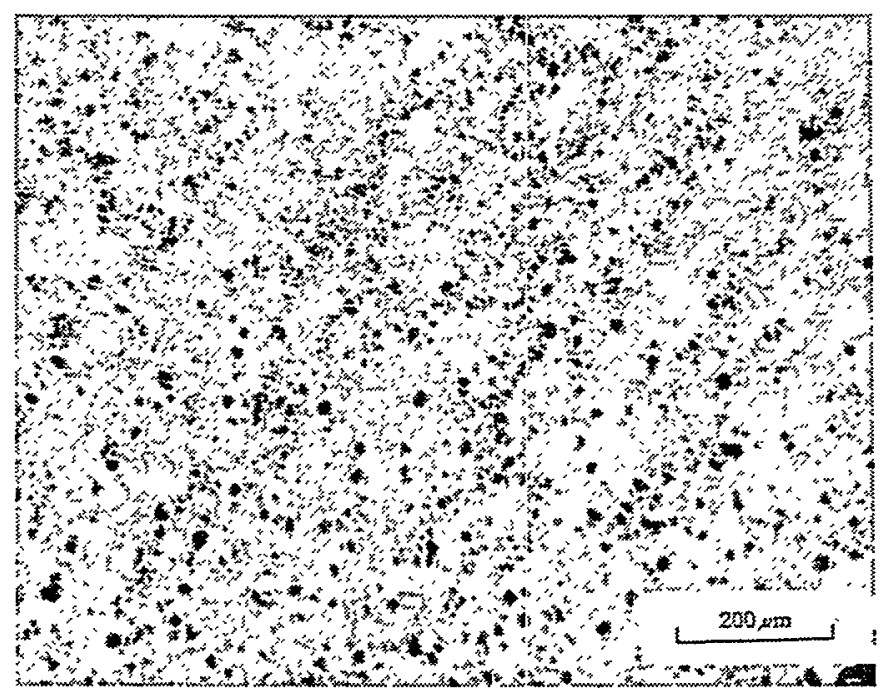

(c) 6061 Aluminum Alloy

Figure 1. Optical photomicrographs of as-received 1100, 5052, and 6061 aluminum alloys. 


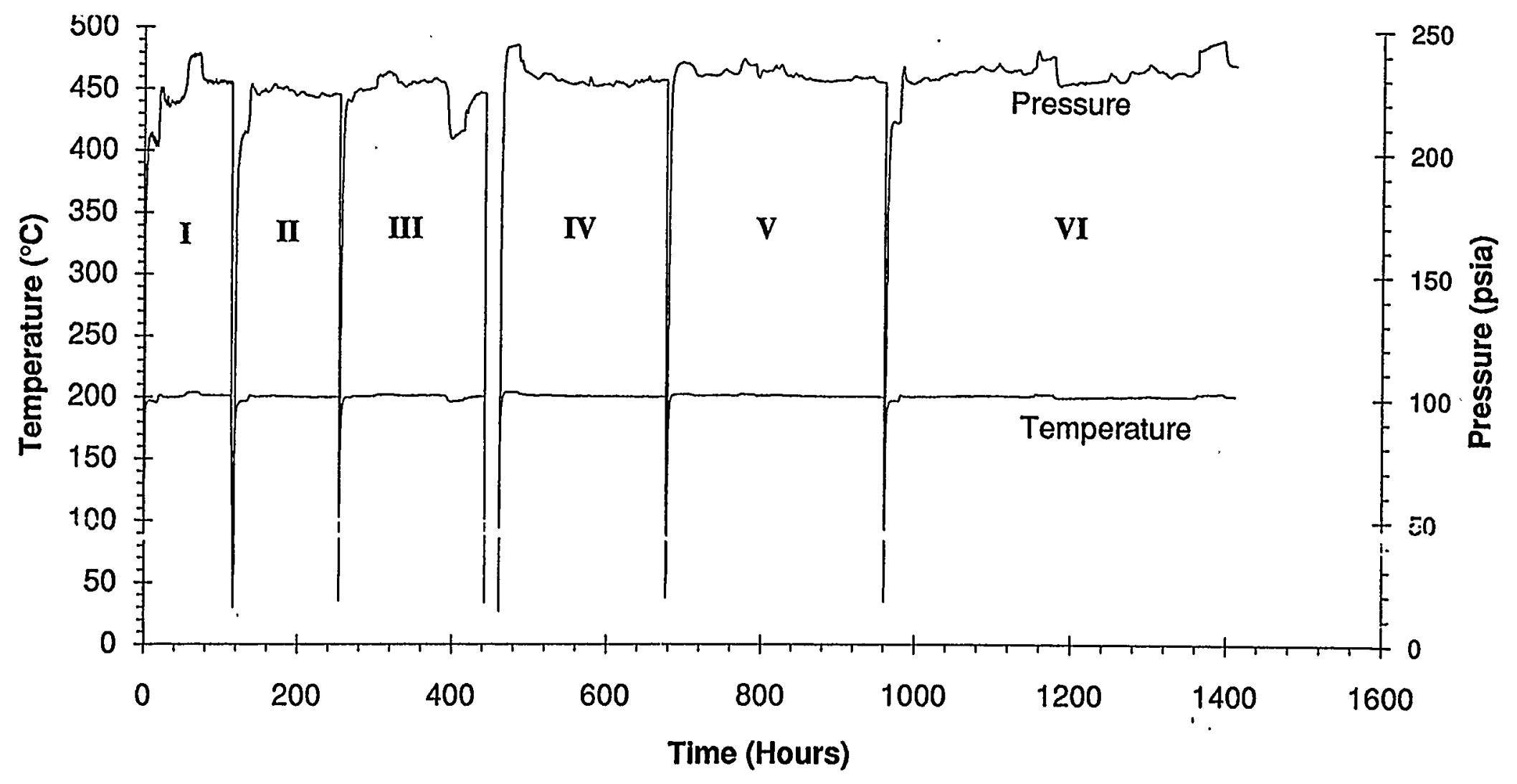

Figure 2. Typical Pressure and Temperature Chart for Corrosion Testing in the Autoclave 

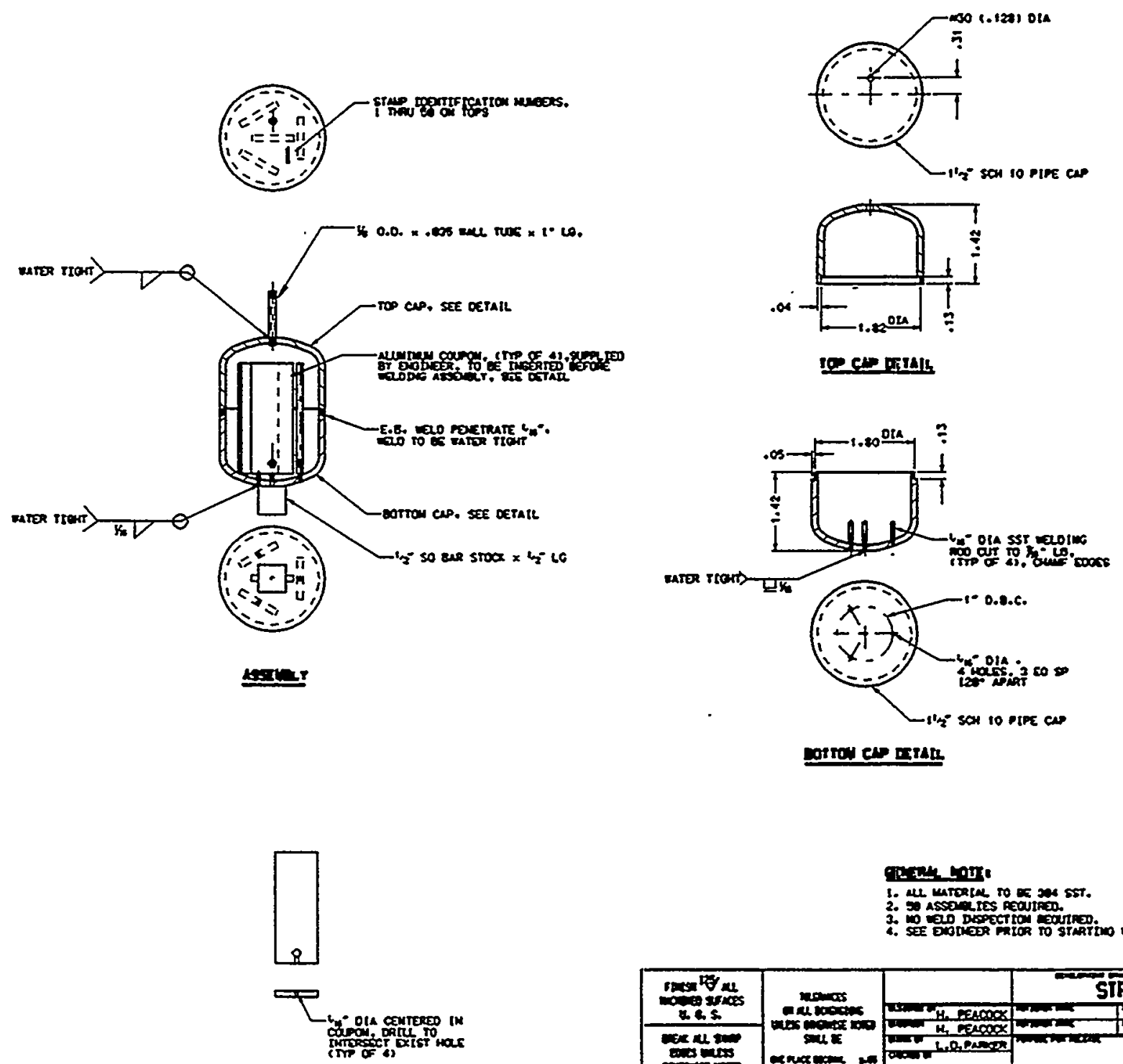

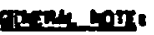

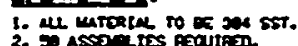

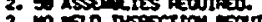

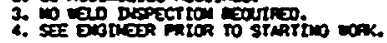

garon trials

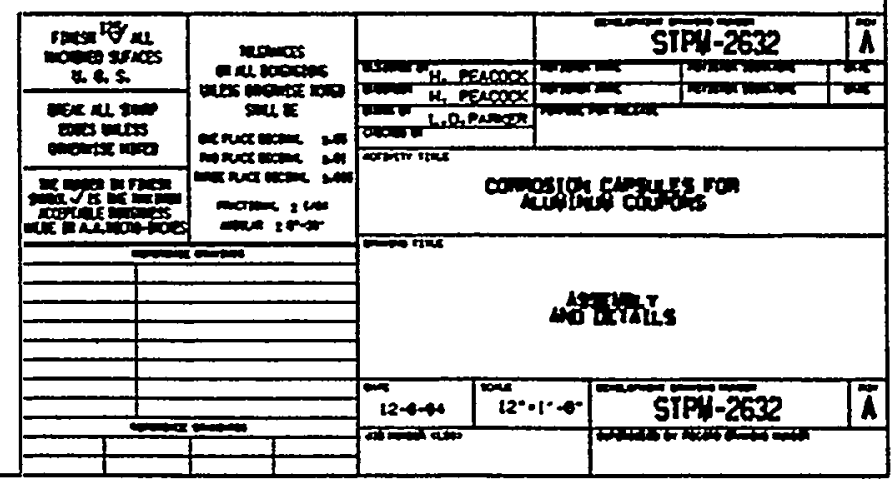

Figure 3. Design Drawing for Corrosion Capsules. 


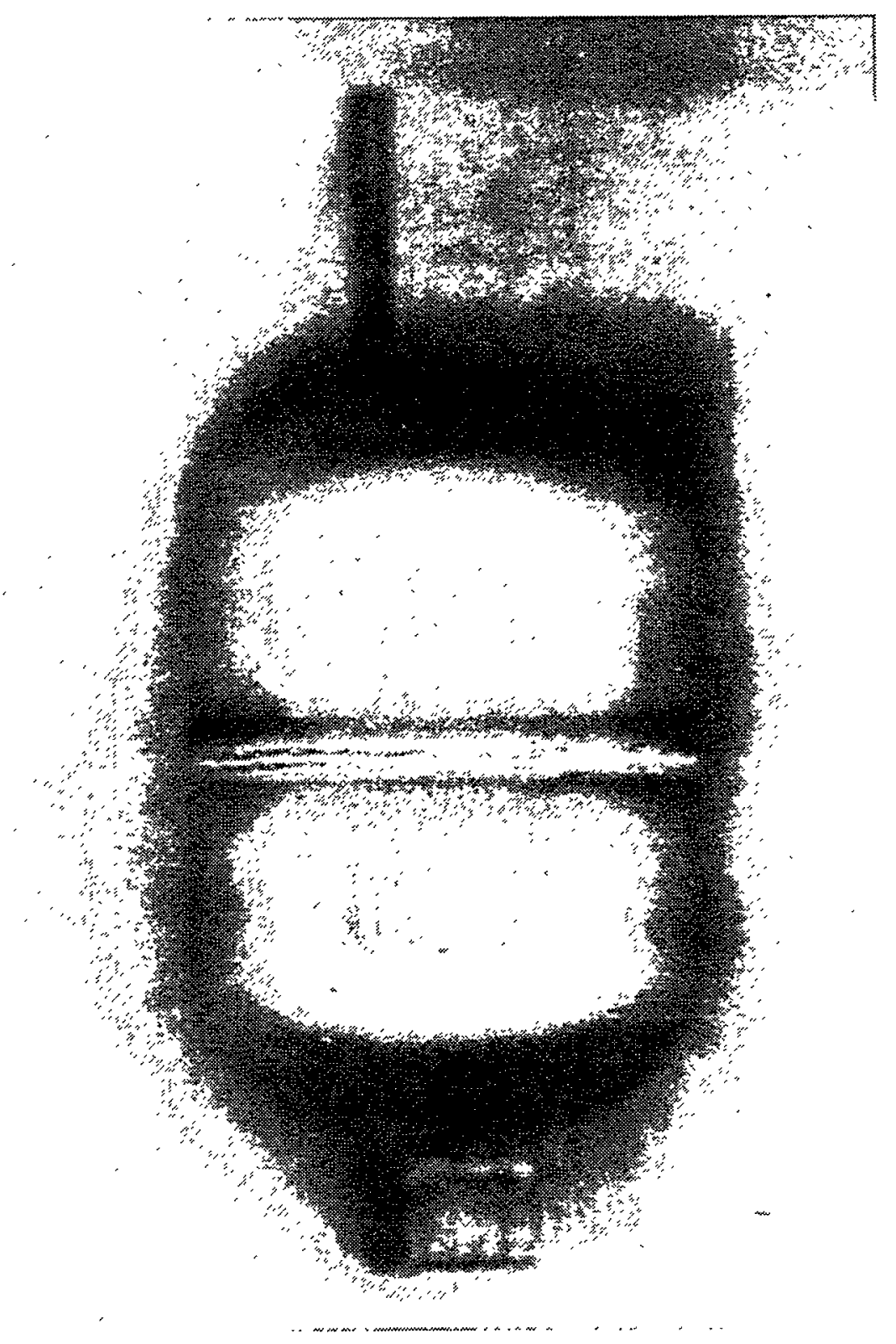

Figure 4. Photograph of fabricated corrosion capsule. 


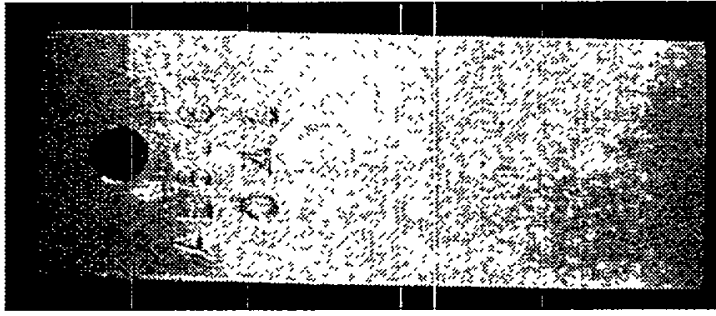

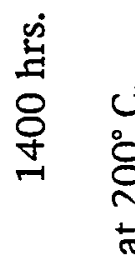

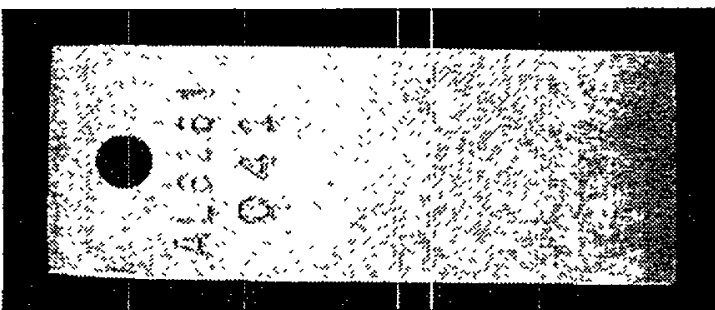

ว

荧

米

융 열
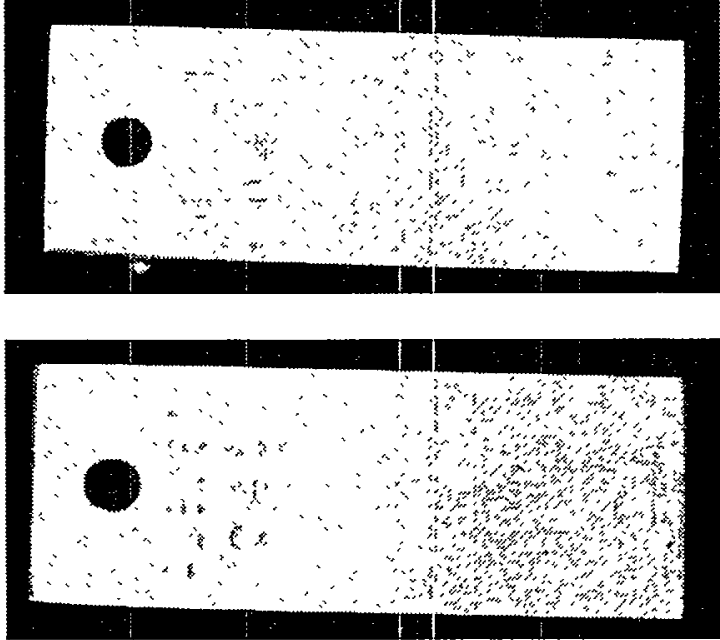

웅

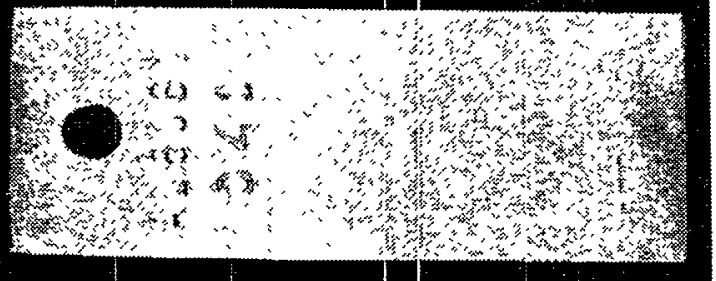

壱 豆
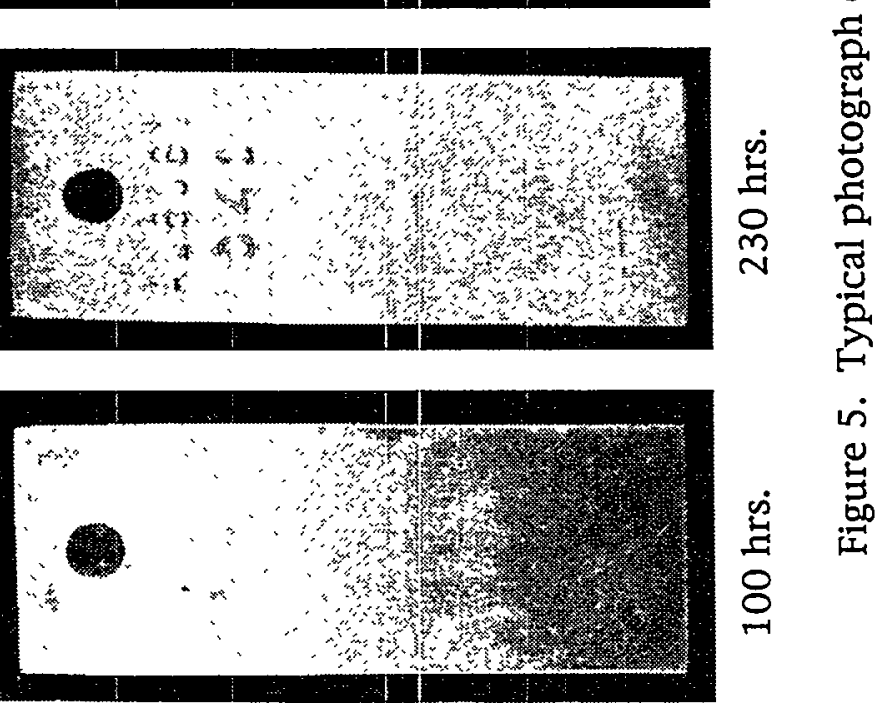

兽 


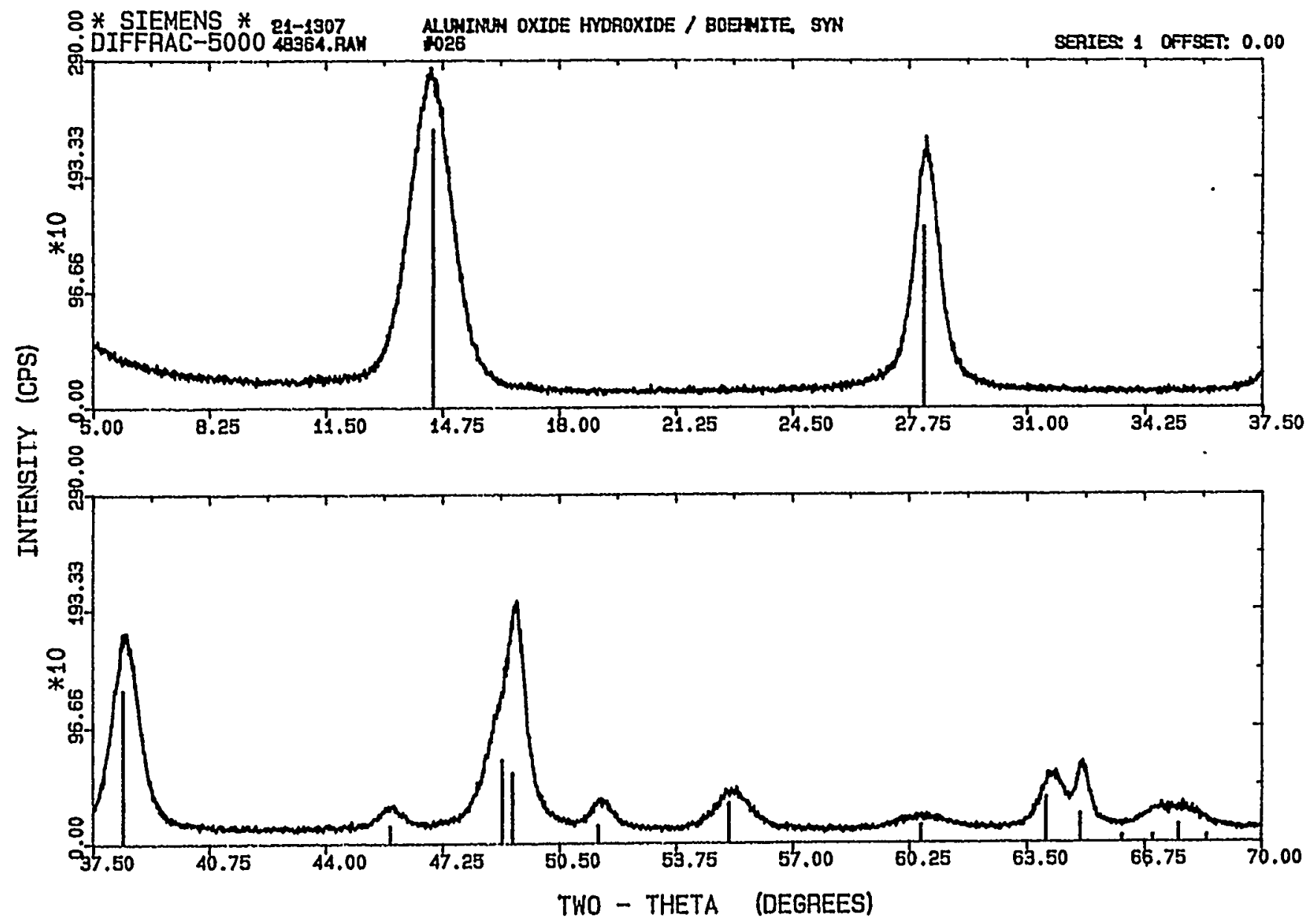

Figure 6. Typical XRD Chart Confirming Boehmite Formation on Corrosion Test Specimens. 


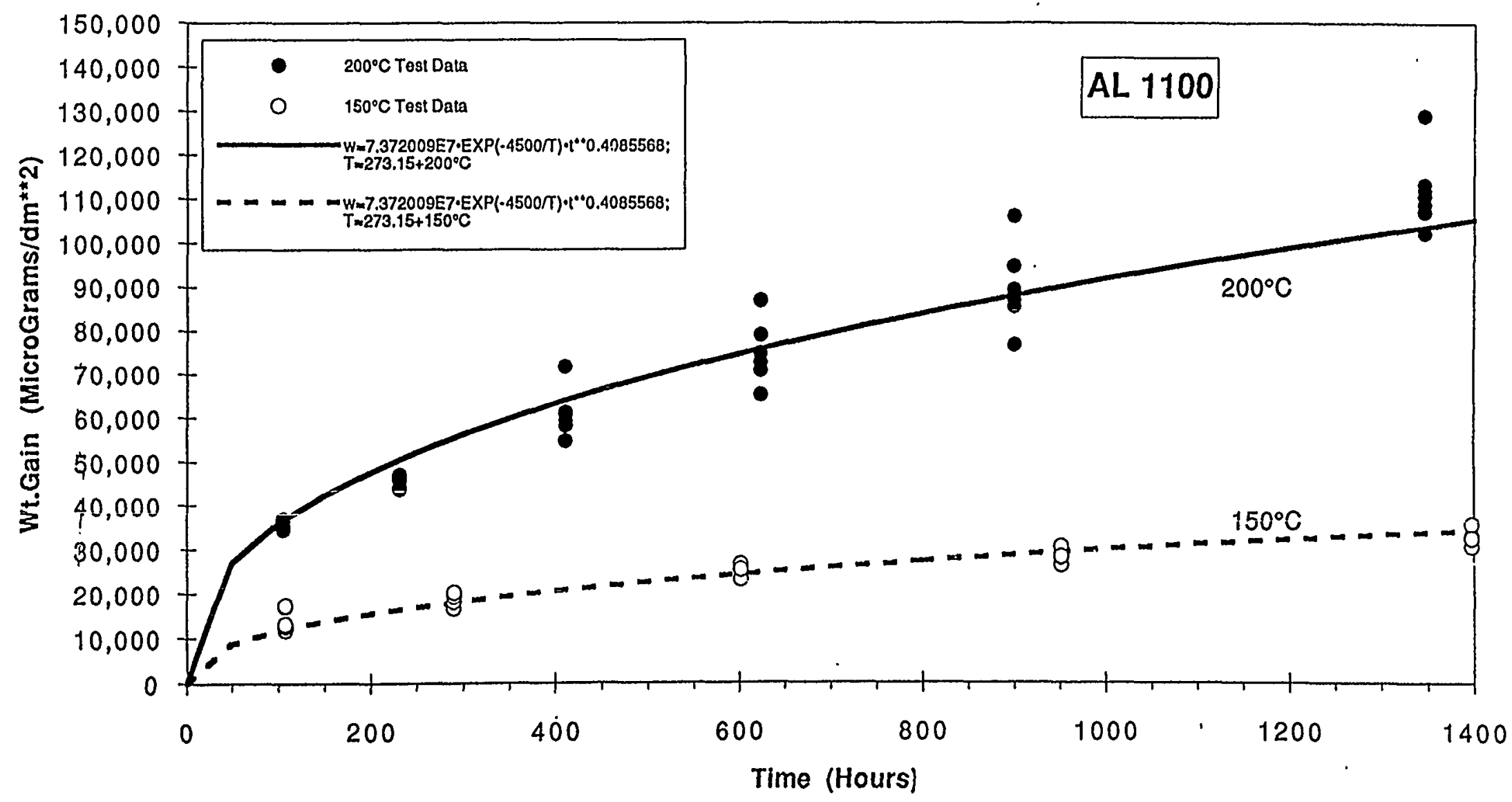

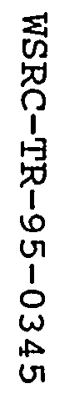

Figure 7. Weight Gain as a Function of Time for 1100 Aluminum at $100 \%$ Relative Humidity and at $150^{\circ} \mathrm{C}$ and $200^{\circ} \mathrm{C}$. 


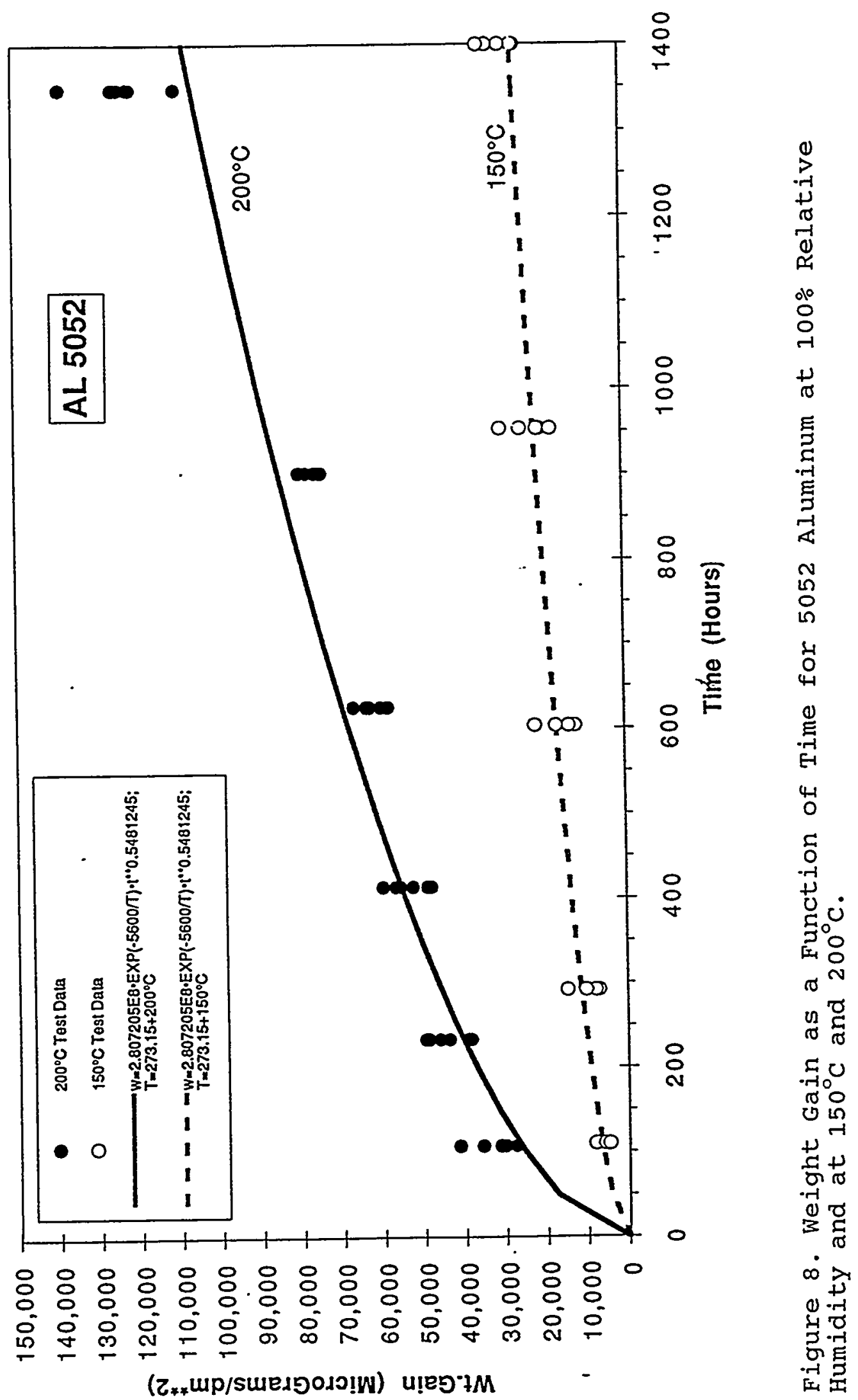




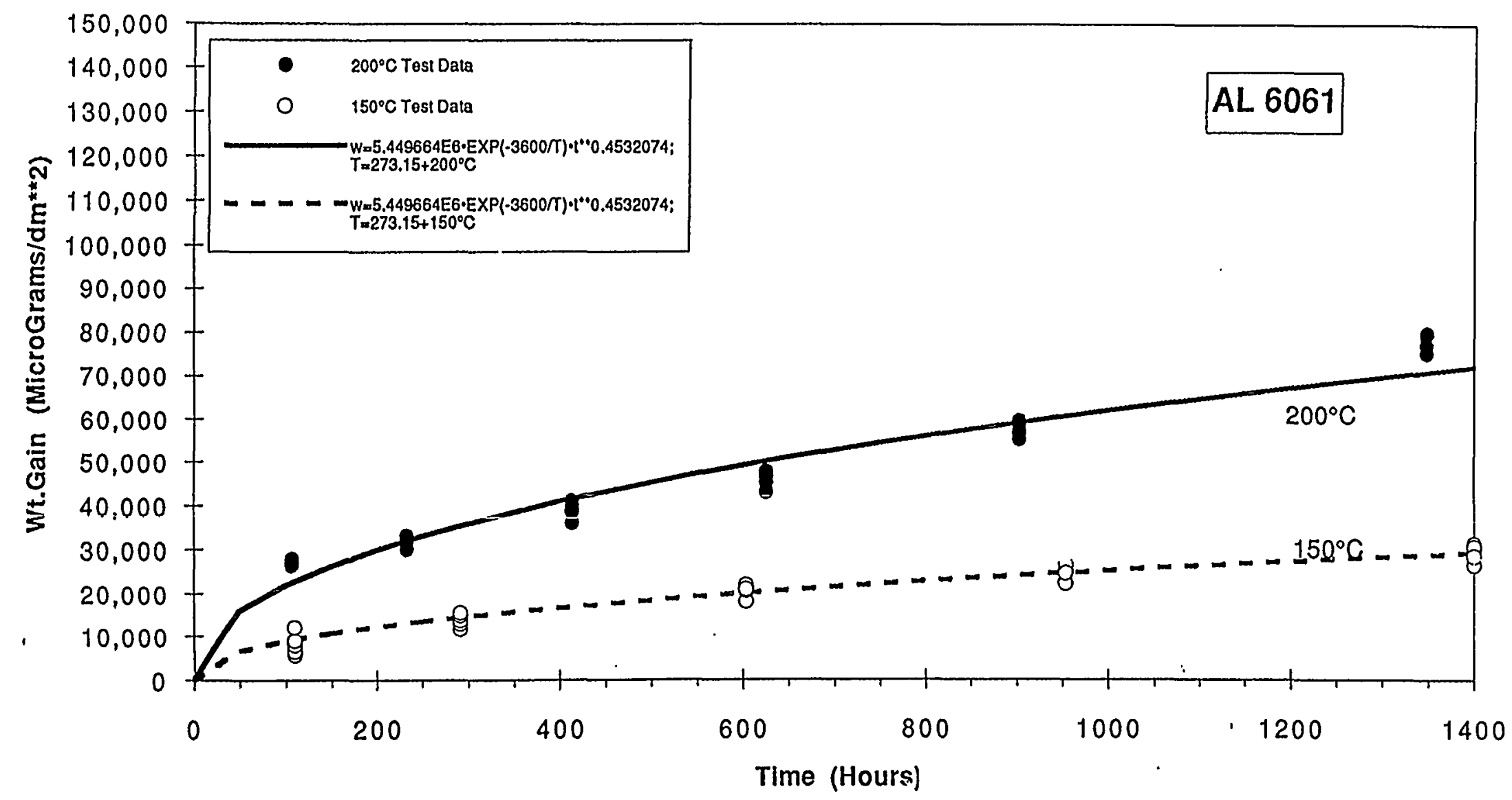

Figure 9. Weight Gain as a Function of Time for 6061 Aluminum at 100\% Relative Humidity and at $150^{\circ} \mathrm{C}$ and $200^{\circ} \mathrm{C}$. 


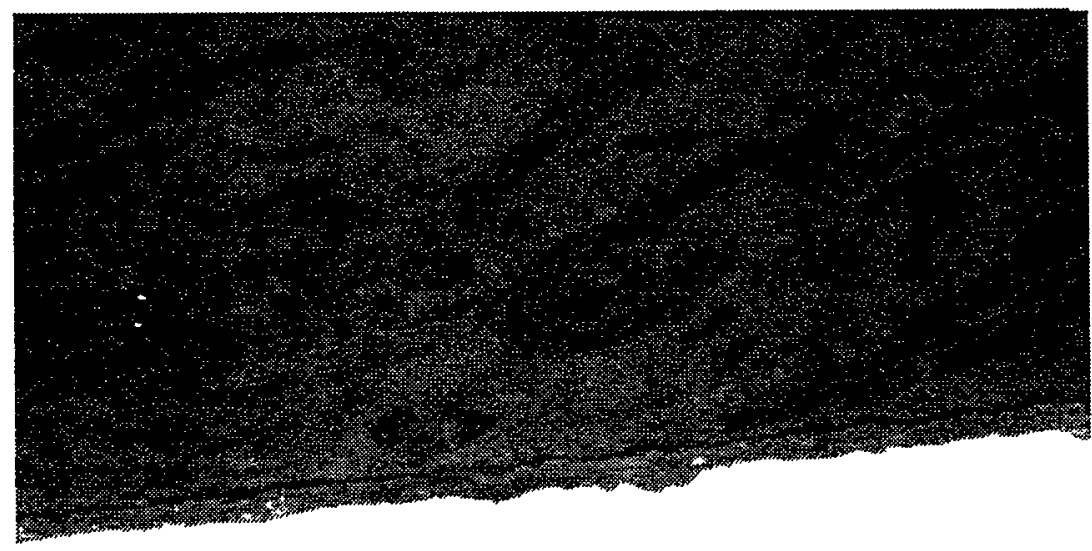

3
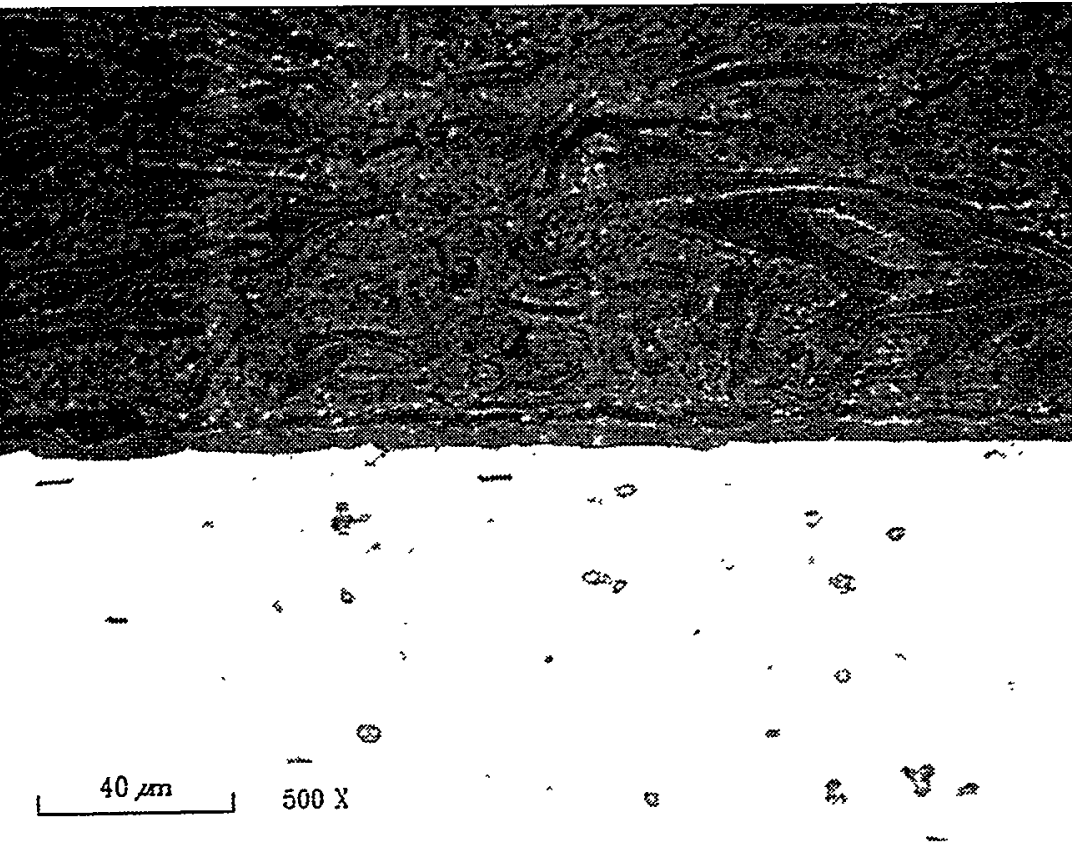

Figure 10. Aluminum oxide on 6061 alloy exposed to saturated water vapor $(100 \% \mathrm{Rh})$ at $200^{\circ} \mathrm{C}$ for 1350 hours. 


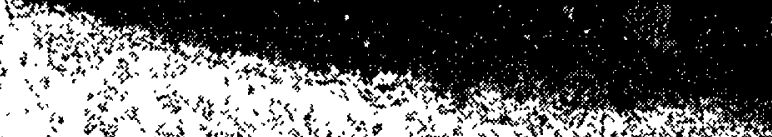

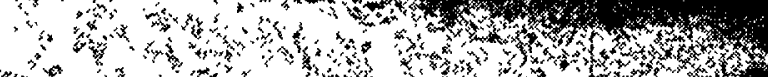

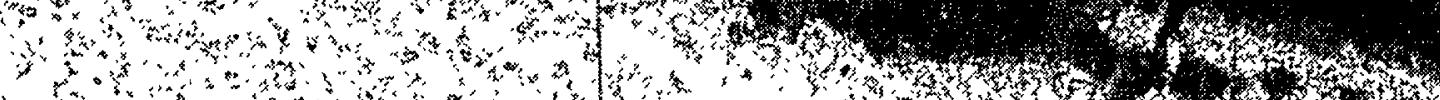

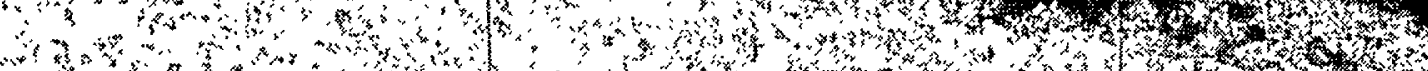

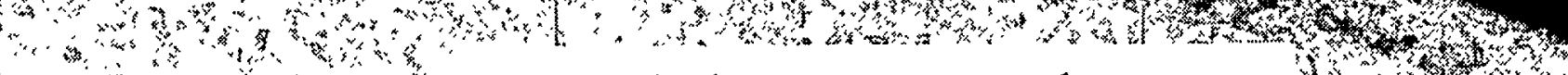

Optical Photomicrograph B. (n)

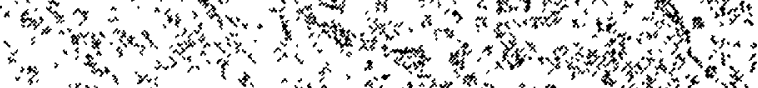

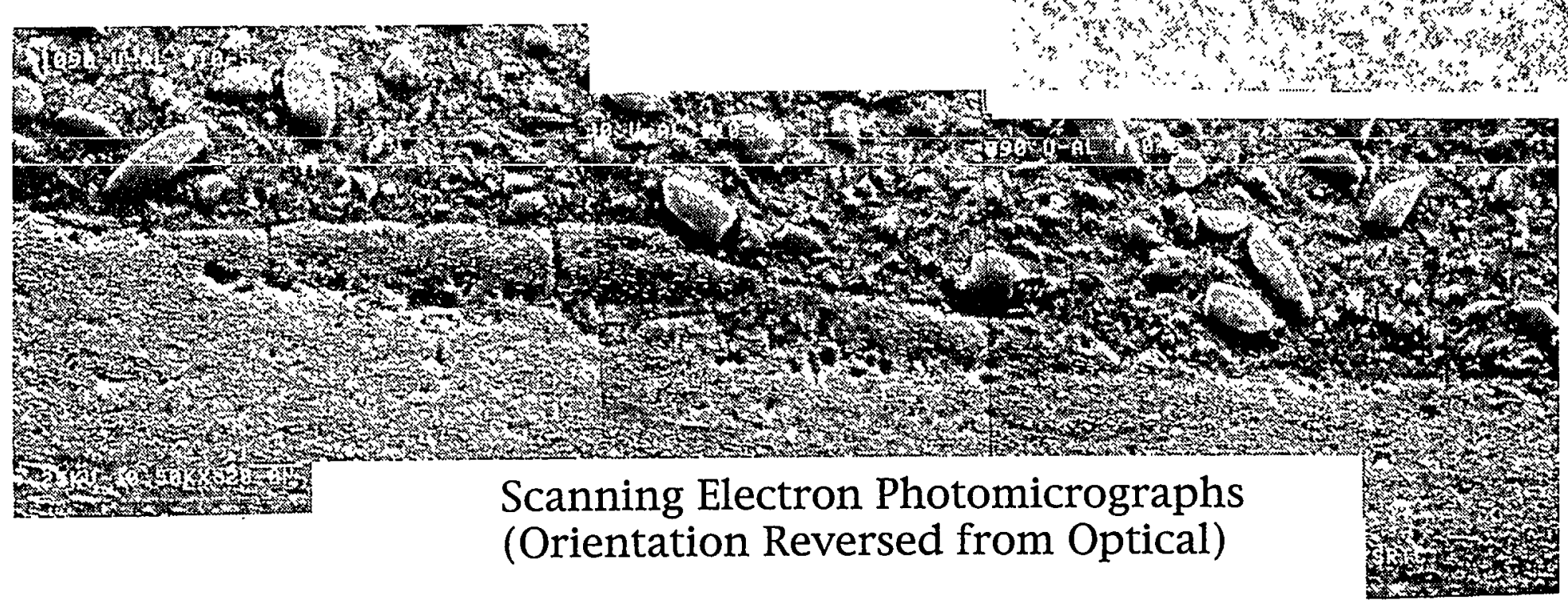

Figure 11. Montage of optical and scanning electron photomicrographs of a blistered area from aluminum-10 wt\% uranium hot rolled alloy exposed to saturated vapor $(100 \% \mathrm{Rh})$ at $200^{\circ} \mathrm{C}$ for four days. (500X reduced $30 \%$.) 


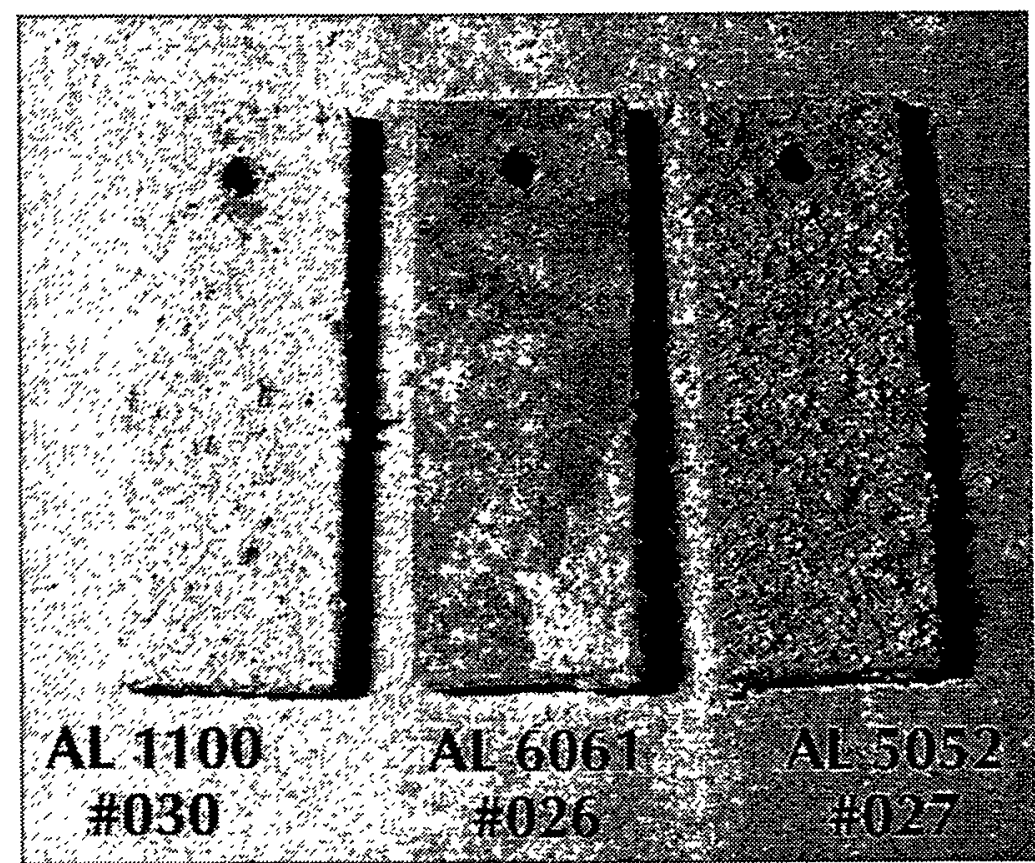

Figure 12. Corrosion of 1100,5052 and 6061 aluminum alloys in an atmosphere containing $\mathrm{NO}_{x}$ gasses and $100 \%$ relative humidity for 1 week. 


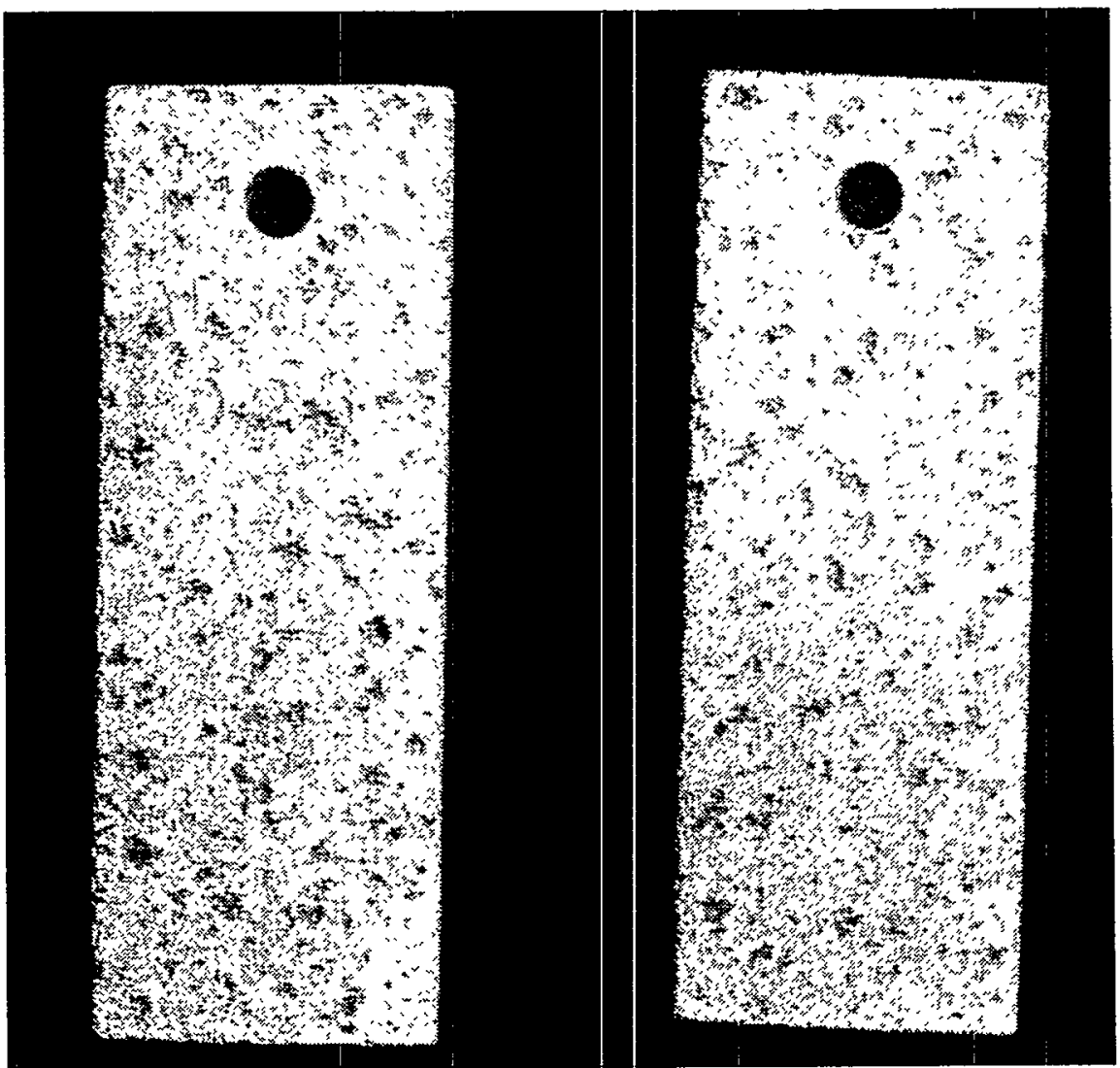

Figure 13. Pitted surfaces of 5052 aluminum alloy exposed to an atmosphere containing $\mathrm{NO}_{\mathrm{X}}$ gases and $100 \%$ relative humidity for one week. 


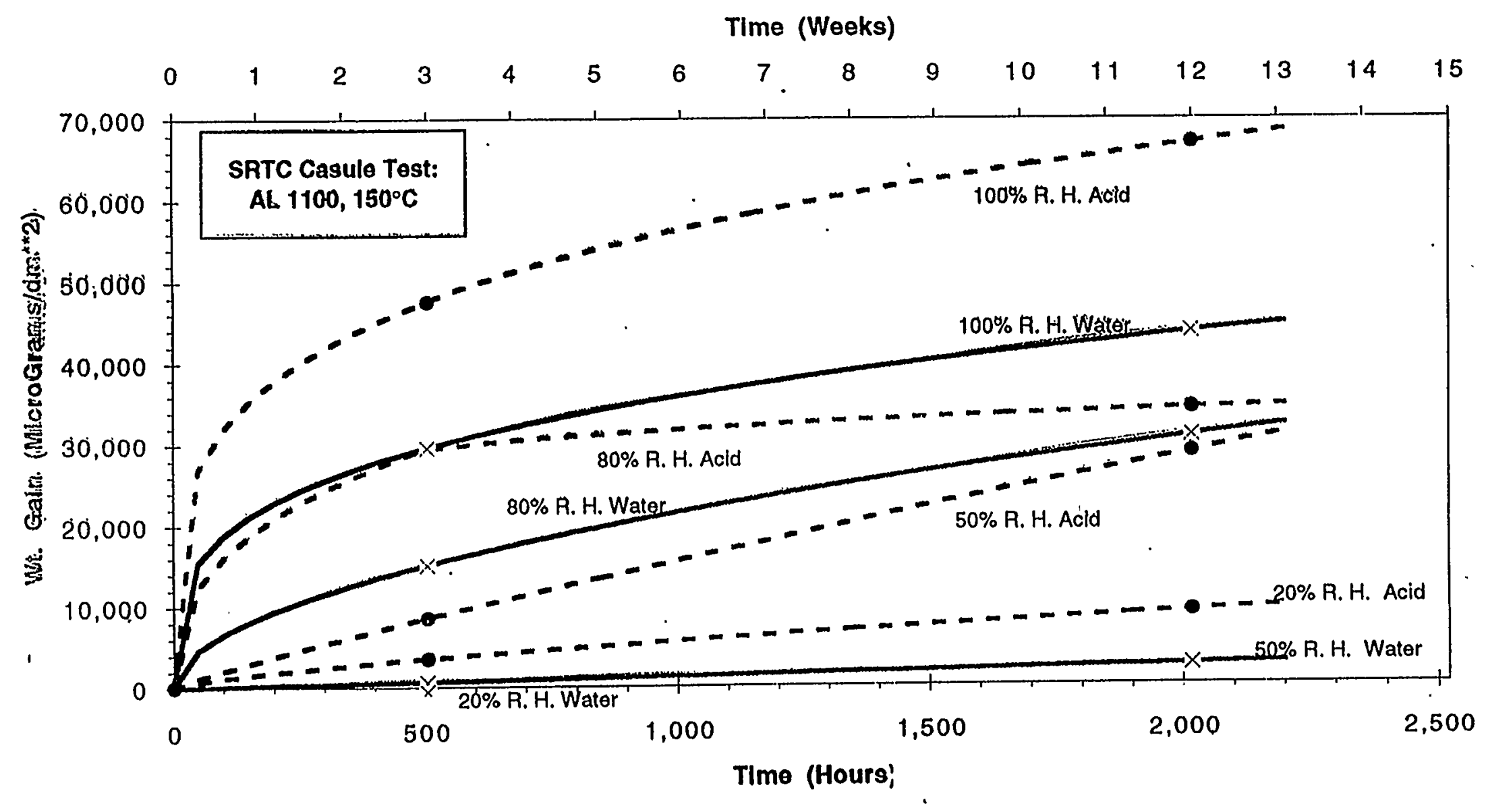

Figure 14. Weight Gain as a Function of Time and Relative Humidity for 1100 Aluminum Alloy either in an Atmosphere of Water Vapor or an atmosphere of Water Vapor and $\mathrm{NO}_{x}$ Gases. 


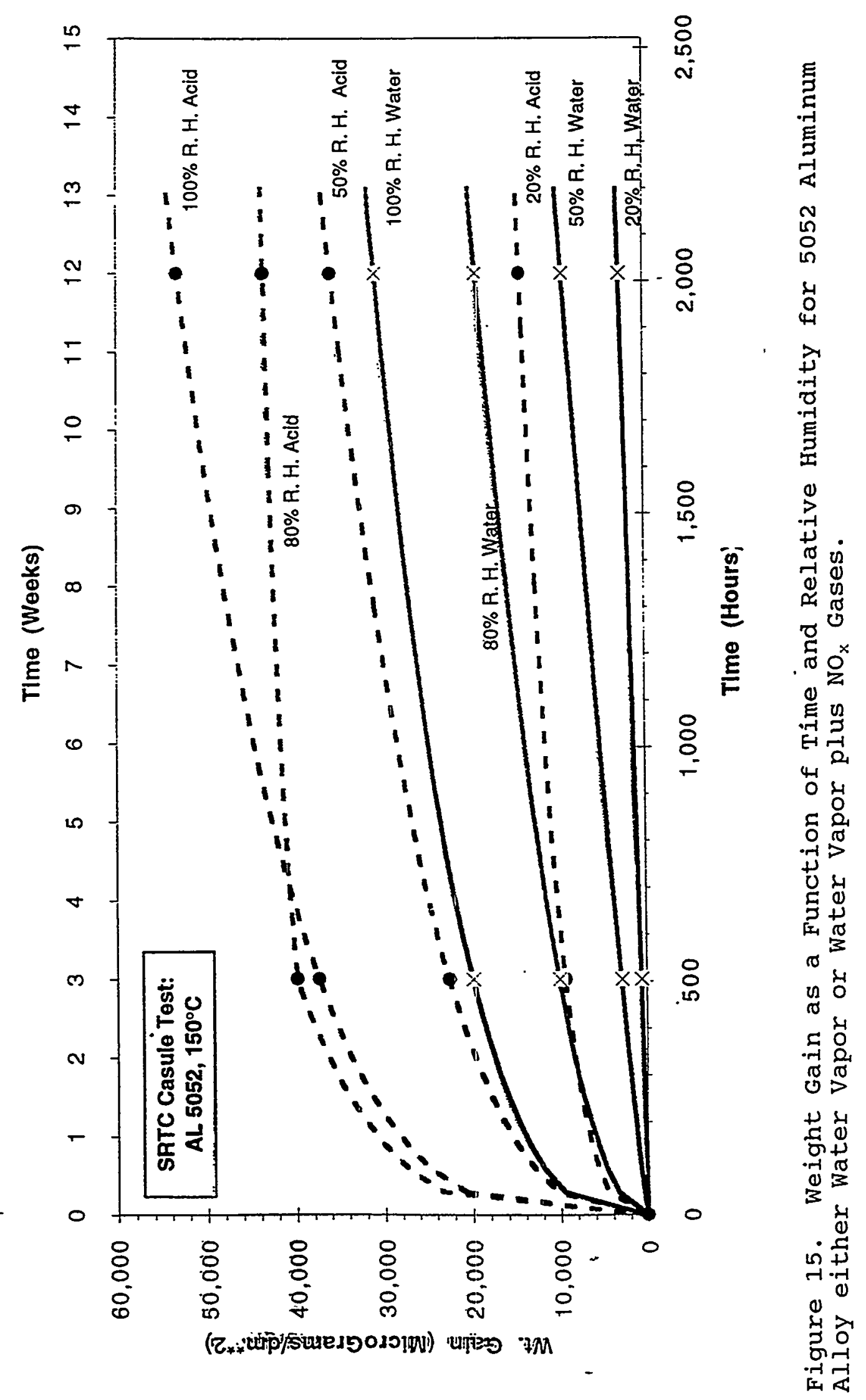




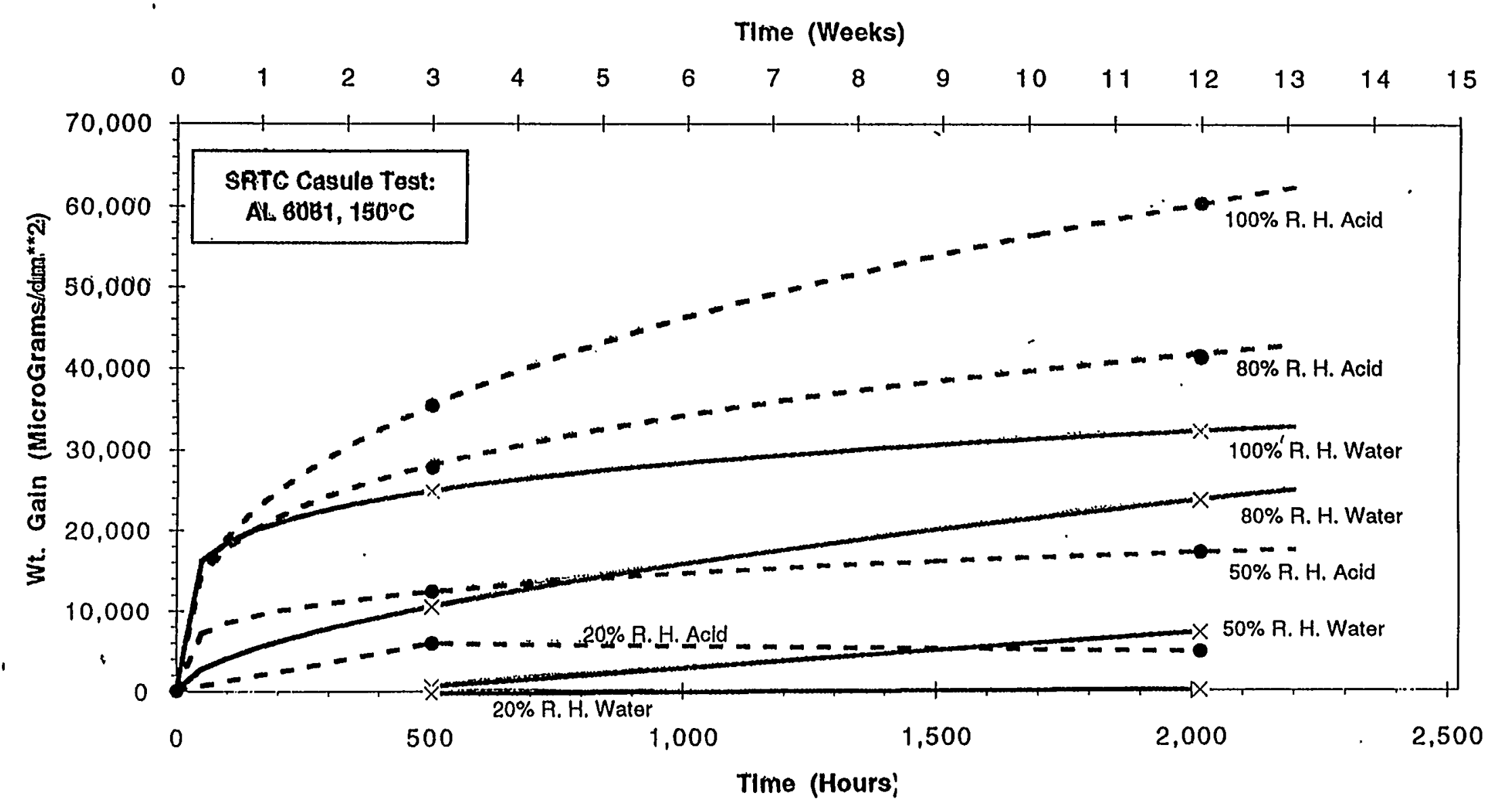

$\sum$
0
0
0
1
1
0
1
6
0
0
1
0
$\omega$
0
0

Figure 16. Weight Gain as a Function of Time and Relative Humidity for 6061 Aluminum Alloy in Atmospheres of Water Vapor and Water Vapor plus $\mathrm{No}_{\mathrm{x}}$ Gases 


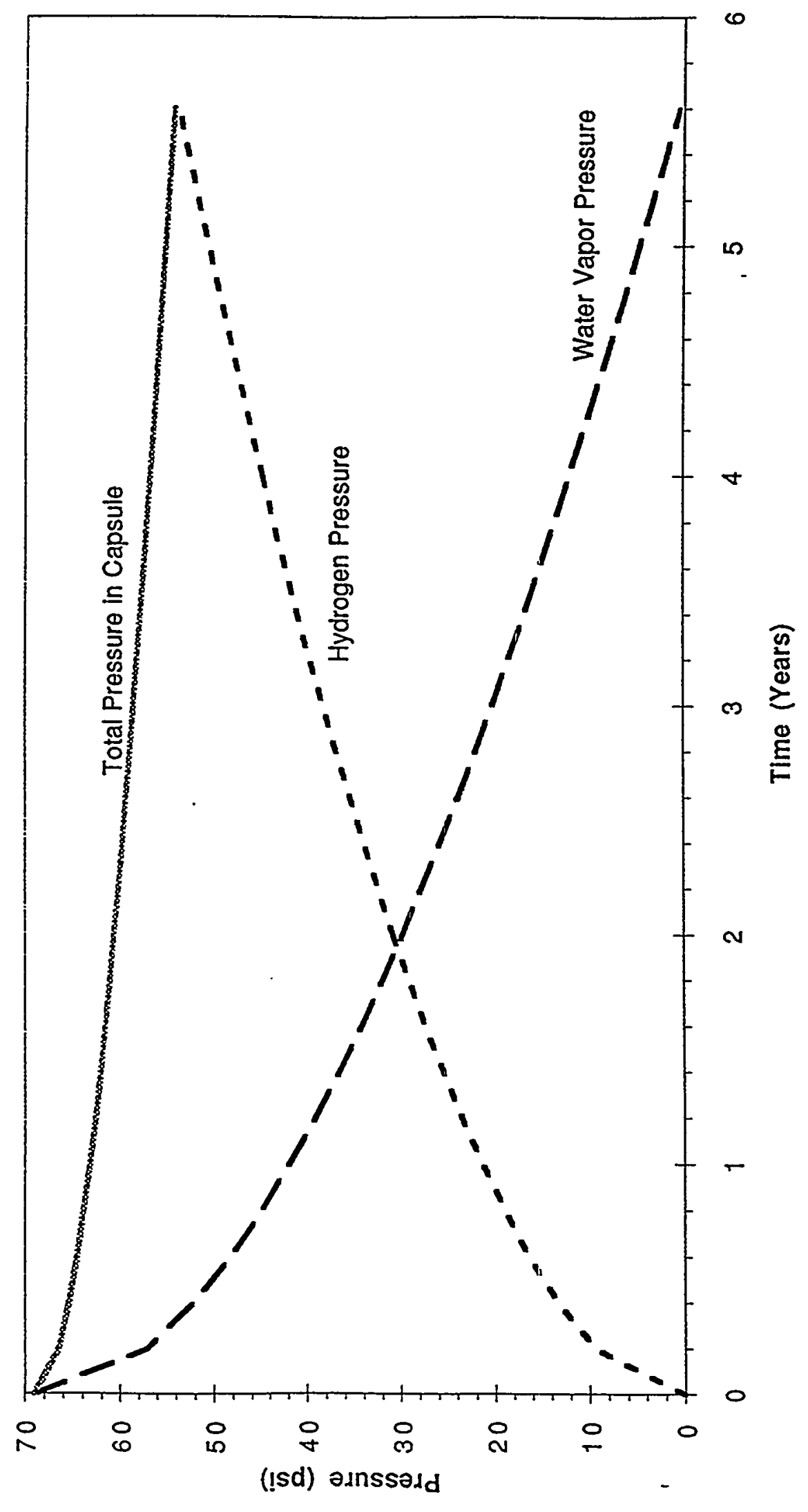

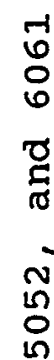

욱

넌

\%

$+\underset{0}{0}$

ก-

ป

तु

00

प्

늘

is

凹

口

U

品

0 के

a

o 0

엉음

岱

足

ช

40

垔

$\stackrel{\infty}{>} n$

4

w.

उ 0

- ช

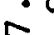

त

()

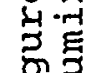

더담 


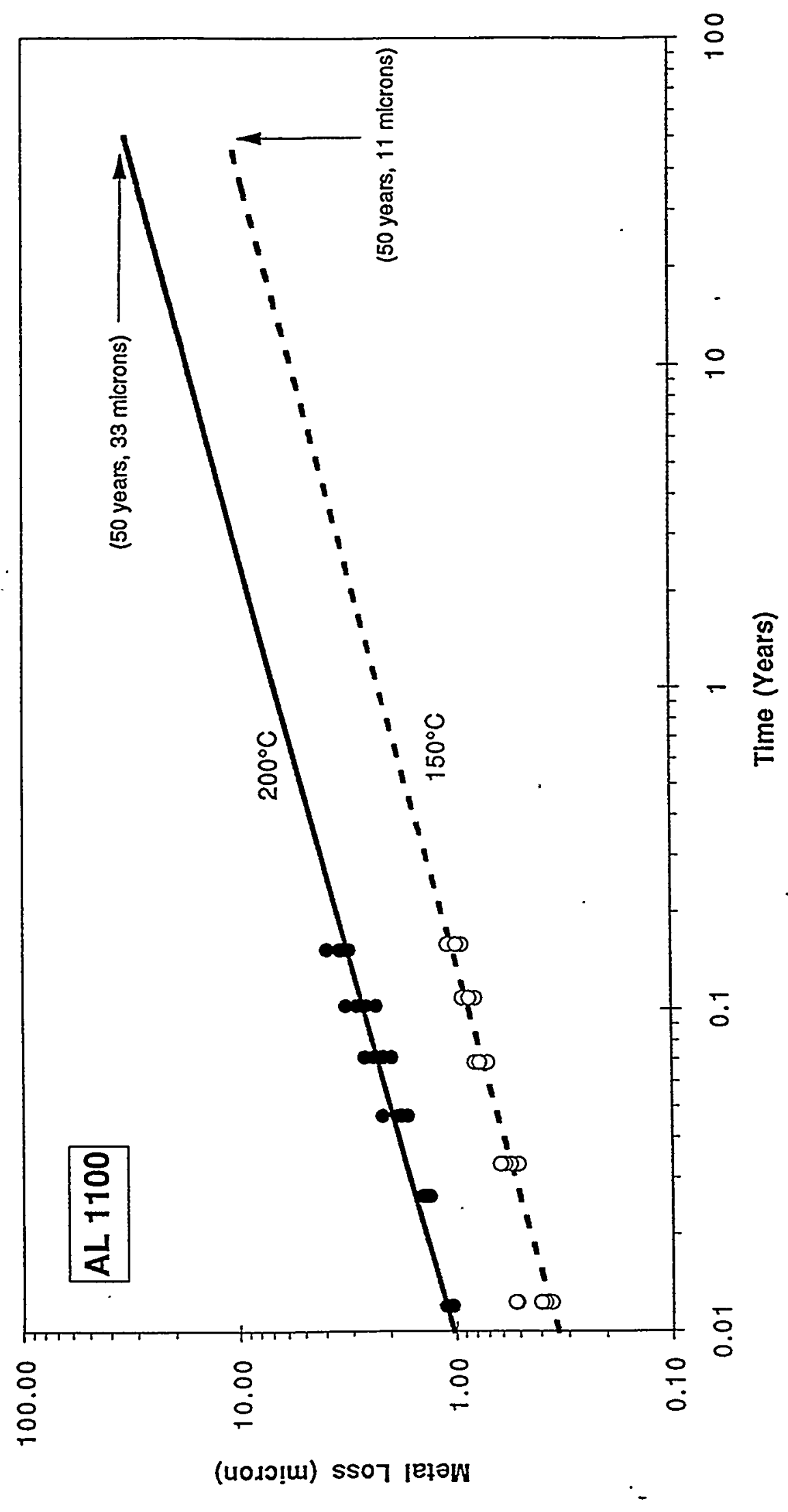

00
0
0
-1
+10
$\pi$
0
0
0

0

0
0
0
0

ర్ర

0
0
0
0

국

$+$

岂

0
$y$
0
0
0
$x$
a

$\stackrel{0}{3}$

Un

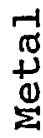

E⿱

$\infty$

$0 .-1$

\&1

हैत

$\rightarrow \stackrel{0}{0}$ 


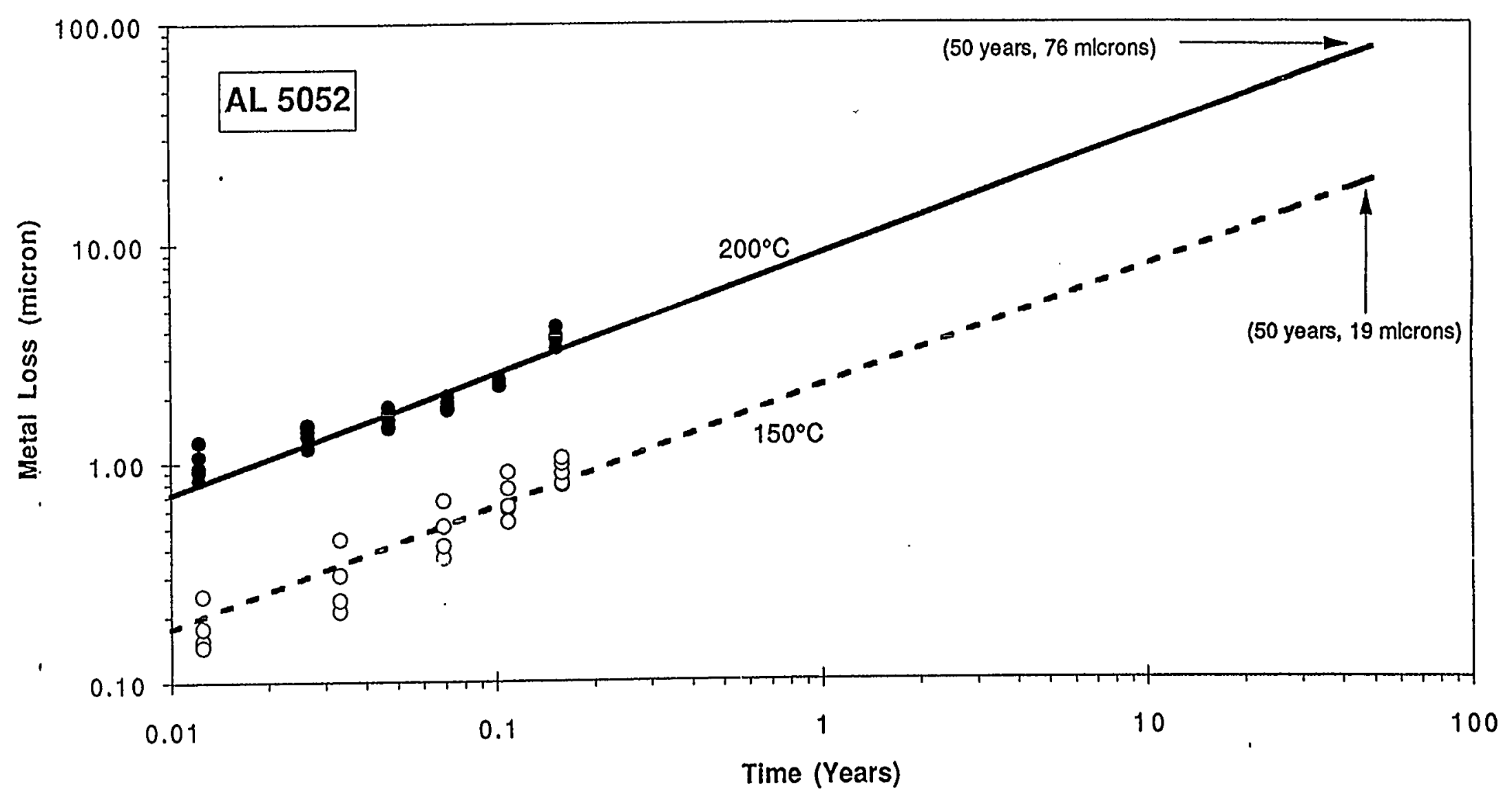

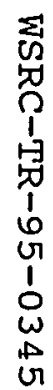

Figure 19. 5052 Aluminum Metal Loss vs Exposure Time at $150^{\circ} \mathrm{C}$ and $200^{\circ} \mathrm{C}$ and at $100 \%$ Relative Humidity. 


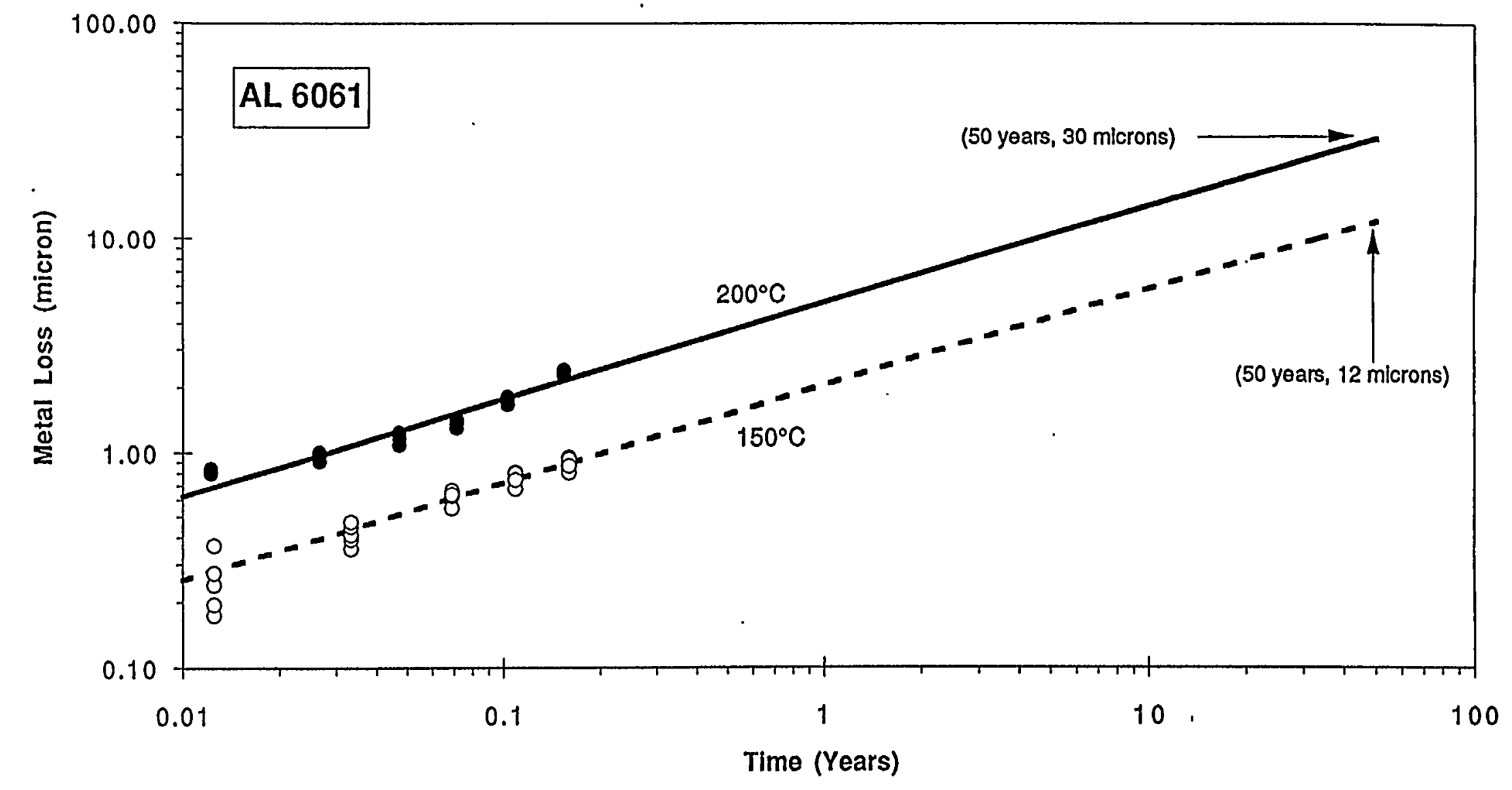

$\Sigma$
0
00
0
1
9
0
1
0
0
1
0
$\omega$
0
0

Figure 20. 6061 Aluminum Metal Loss vs Exposure Time at $150^{\circ} \mathrm{C}$ and $200^{\circ} \mathrm{C}$ and at $100 \%$ Relative Humidity. 

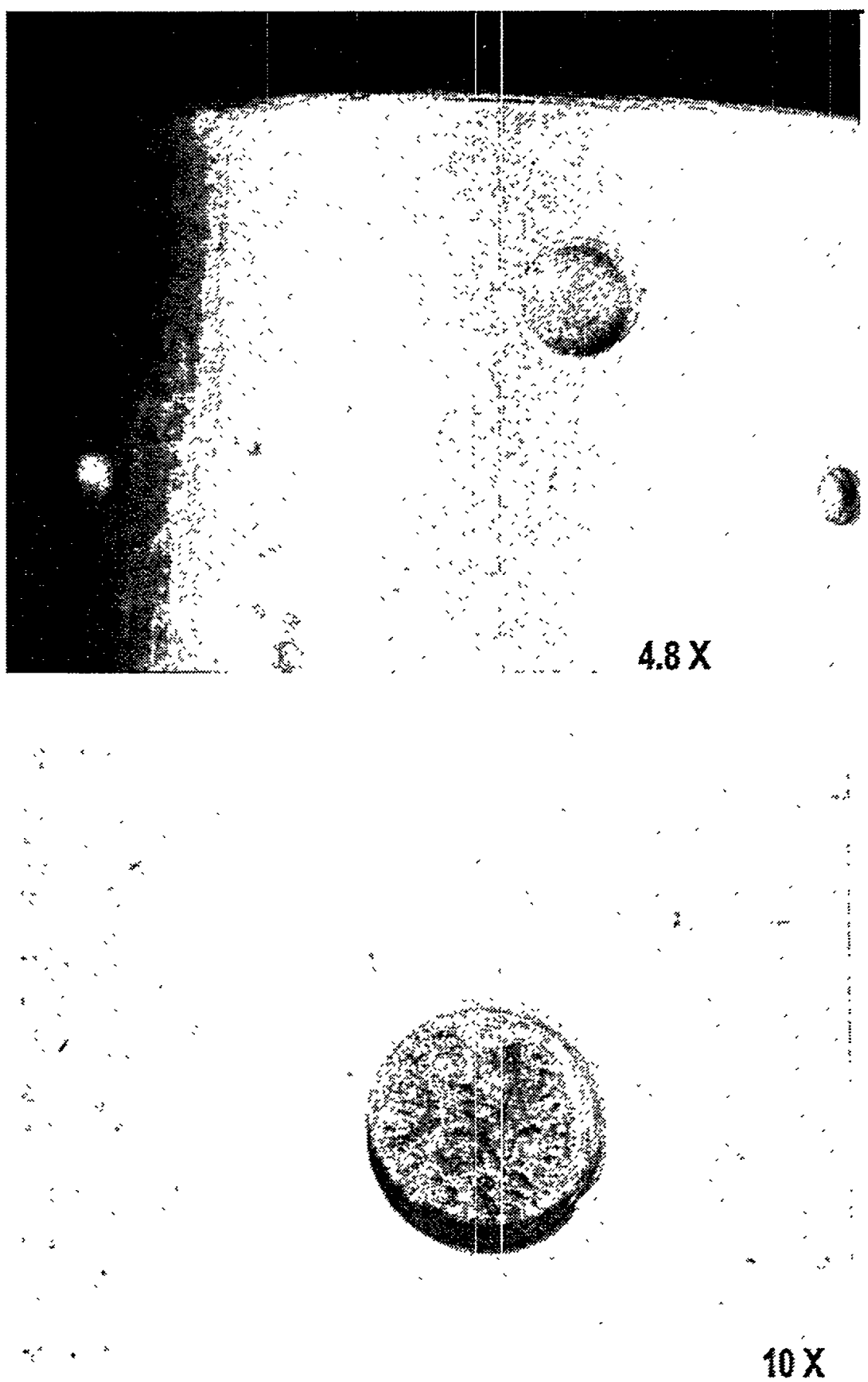

Figure 21. Corrosion inside a $3.2 \mathrm{~mm}$ diameter pit exposed to saturated water vapor ( $100 \% \mathrm{Rh})$ for 1 month. 
WESTINGHOUSE SAVANNAH RIVER CO. REPORT WSRC-TR-95-0345

DISTRIBUTIION

SAVANNAH RIVER SITE

E. R. Conatser, 707-C

J. R. Murphy, 707-C

M. E. Dupont, 707-C

B. D. Clark, 707-C

T. L. Capeletti, 773-41A

IN: C. Iyer, 773-A

M. R. Louthan, Jr., 773-A

J. P. Howell, 773-41A

H. B. Peacock, Jr. (5), 773-A

P. E. Zapp, 773-A

J. I. Mickalonis, 773-A

B. J.-Wiersma, 773-A

P. S. Lam, 773-41A

T. H. Murphy, 773-A

R. L. Sindelar (5), 773-41A

W. F. Ayers, 773-41A

Records Storage, 773-52A 